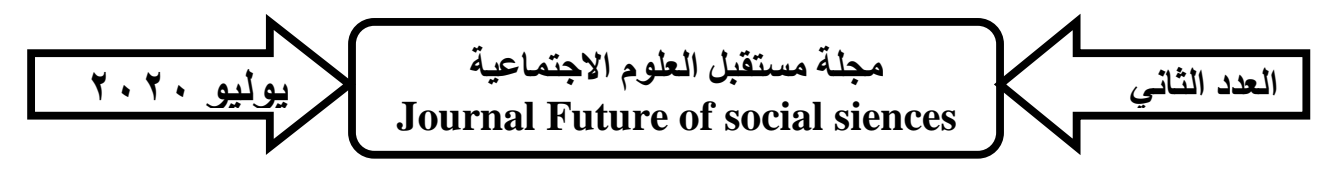

\title{
بناء نموذج لإدارة الحالة لتحسين نوعية حياة الأطفال بلا هأوى
}

Designing a model of case management for improving the life quality of homeless children

\author{
إعداد \\ إيهاب هامد سالم على \\ مدرس خدمة الفرد \\ كلية الخدمة الإجتماعية \\ جامعة حلوان
}

$$
r \cdot r \cdot
$$




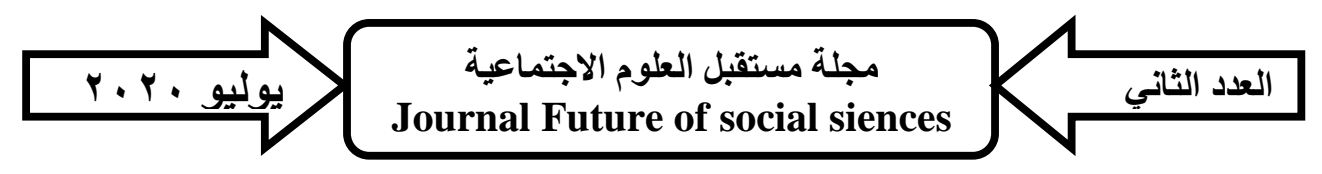




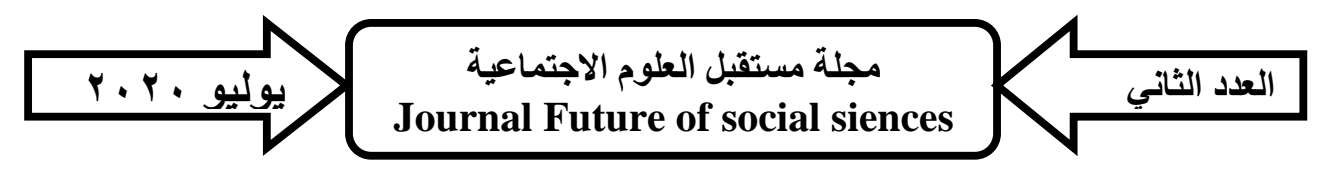

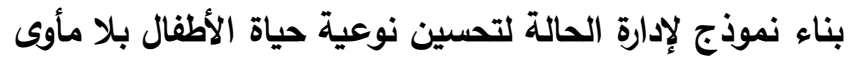

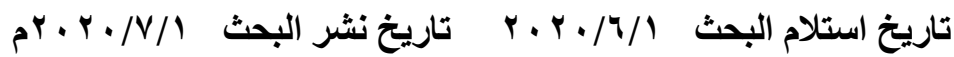

مستخلص:

تعتبر تلك الدراسة من الدراسات الوصفية التي تستهدف بناء نموذج لإدارة الحالة لتحسين

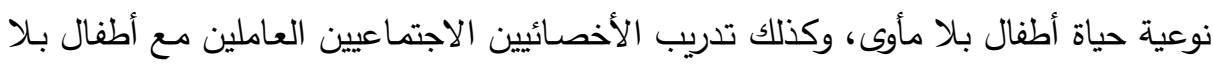

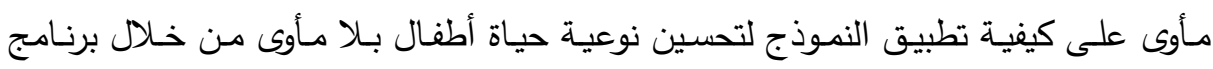

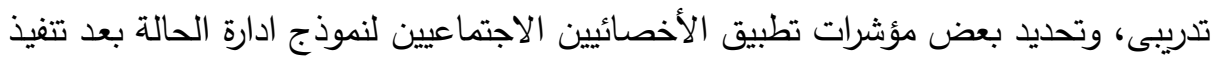
البرنامج التدريبى، وقد توصلت الدراسة إلي الإجابة علي كافة تساؤلاتها. الكلمات المفتاحية: نموذج إدارة الحالة، تحسين نوعية الحياة، أطفال بلامأوى. لون.

\section{Abastract:}

This study is considered one of the descriptive studies aimed at building a case management model to improve the quality of life of homeless children, as well as training social workers working with homeless children on how to apply the model to improve the quality of life of homeless children through a training program, and to identify some indicators of social workers' application of the model Case management after implementing the training program, and the study reached an answer to all its questions.

Key words: Case Management Model - Improving Quality of Life Homeless Children

$$
\text { أولاً: مقدمة الدراسة: }
$$

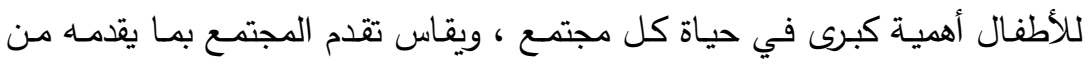

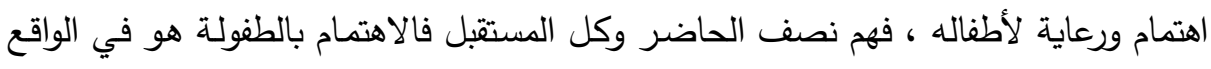

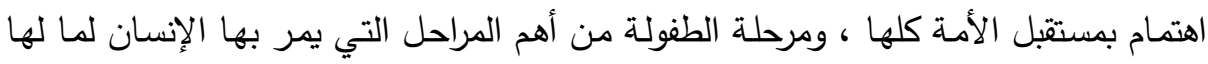

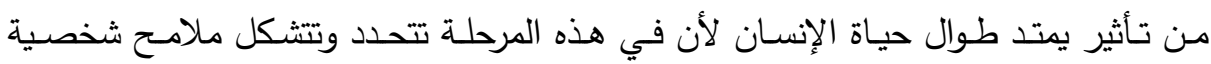

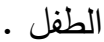

قد يتعرض هؤلاء الأطفال إلى بعض الظروف السلبية سواء كانت أسرية متمثلة في

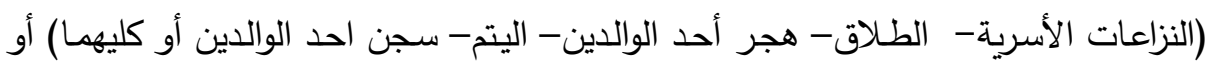

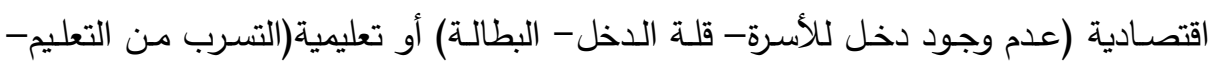
الهروب من المدرسة- الأمية) يؤدى بهم إلى وجودهم ضمن فئة أطفال بلا مأوى . 


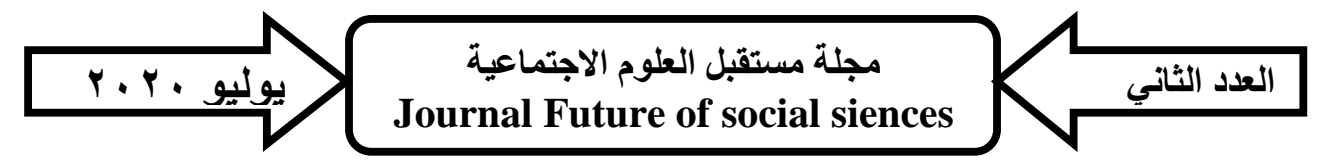

وترتبط ظاهرة أطفال بلا مأوى - مثل اى ظاهرة اجتماعية - بالظروف الإجتماعية

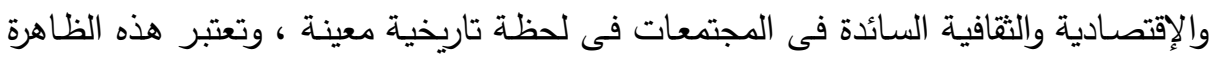

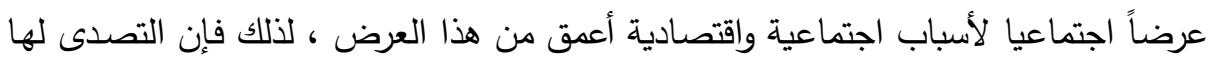

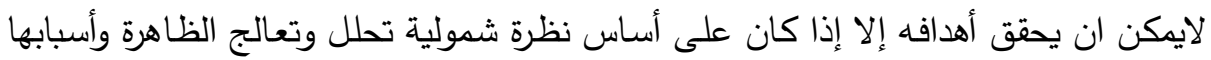

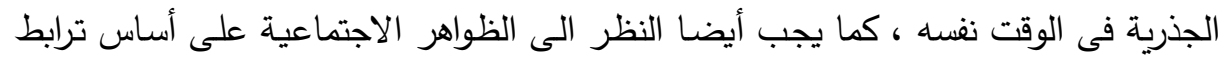

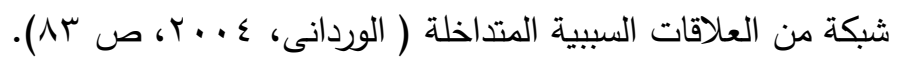

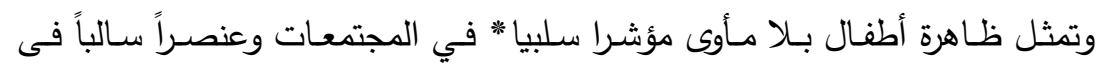

التتمية المستديمة التى تتشدها الحكومات لضمان القضاء عليها ومنع تكرارها .ويبين الثكل

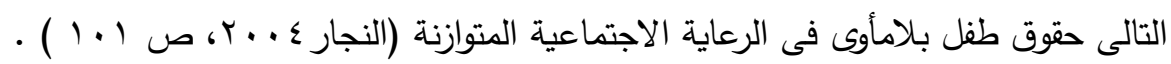
شكل (1) يوضح الرعاية الاجتماعية المتوازنة لأطفال بلا مأوى

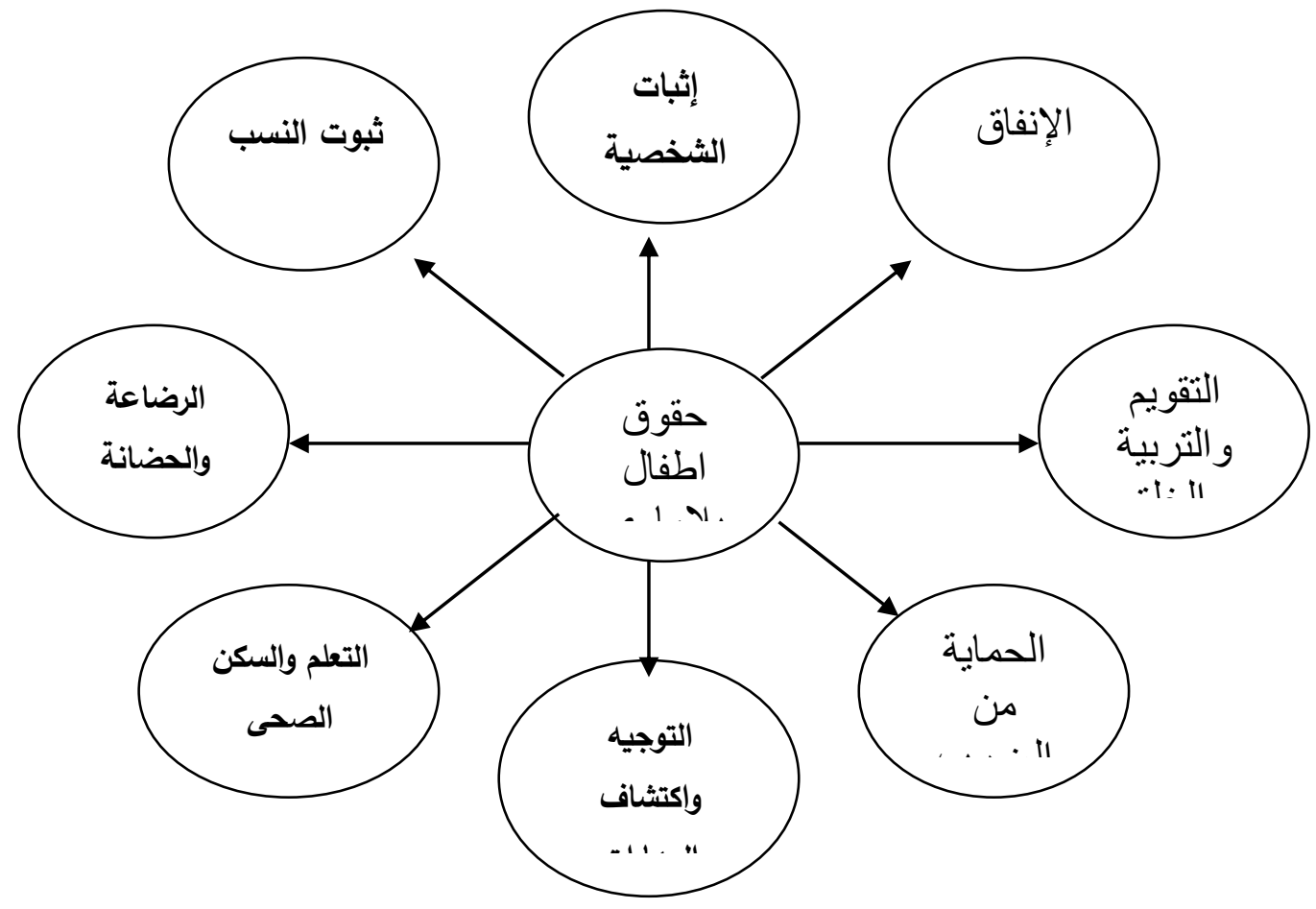

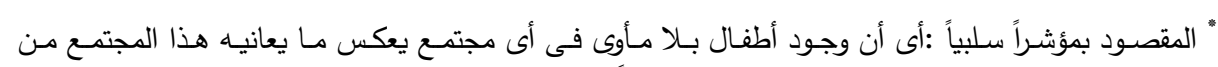

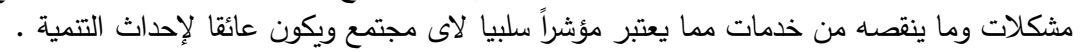




\section{r.r. يوليو \\ مجلة مستقبل العلوم الاجتماعية \\ Journal Future of social siences}

يوضـح شكل رقم (1) ما يجب تقديمه من رعاية اجتماعية للطفل بـلا مأوى وهى الطي

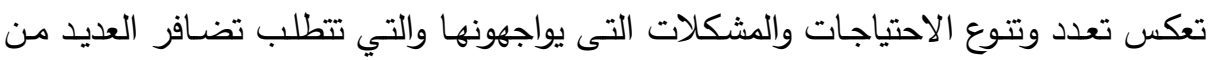

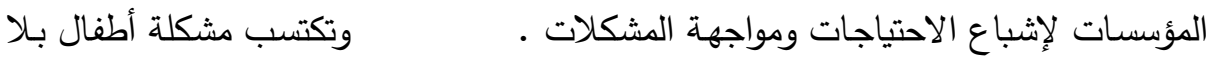

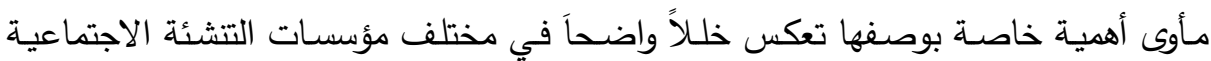

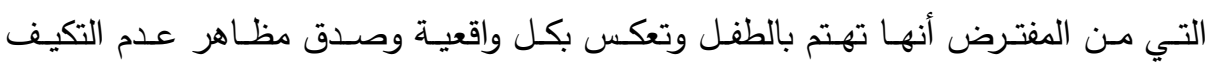

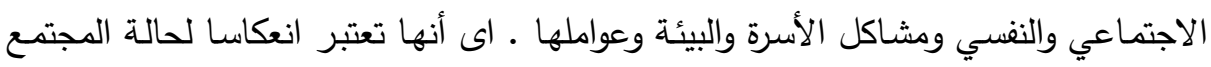
بمختلف مؤسساته وما وصلت إليه تلك المؤسسات من تدهور أو قصور فى القيام بأدوارها

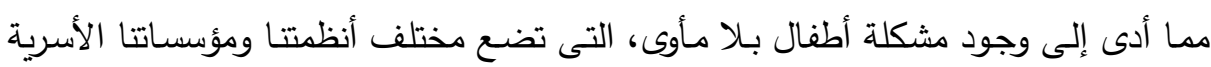

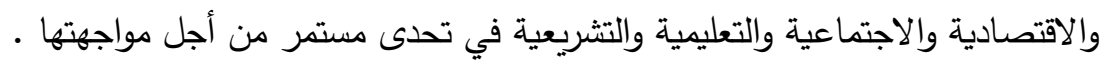

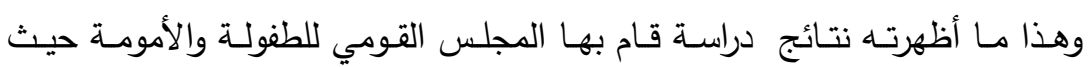
توصلت إلى عدم وجود سبب أو أسباب معينة لتواجد الطفل أو الطفلة في الثارع لان الطفل

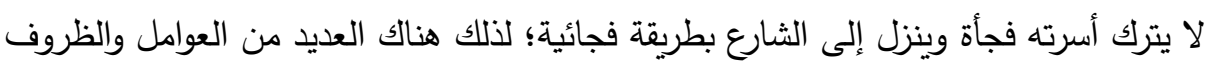

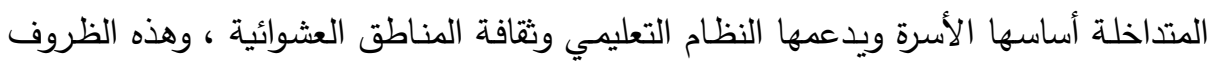

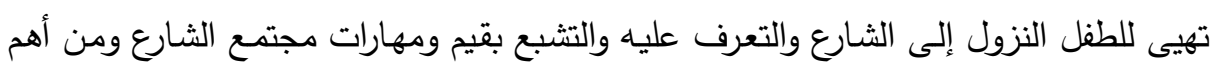

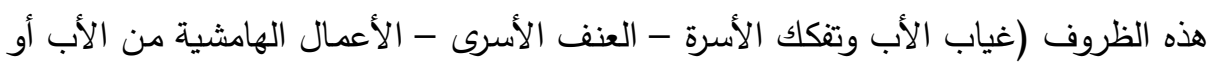

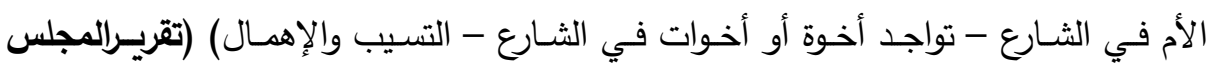

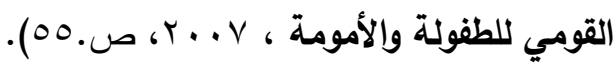

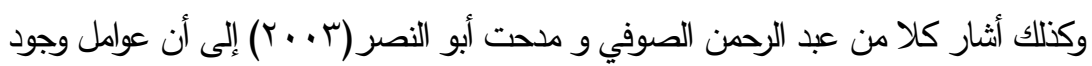

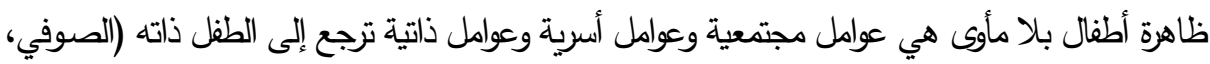

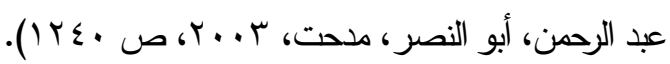

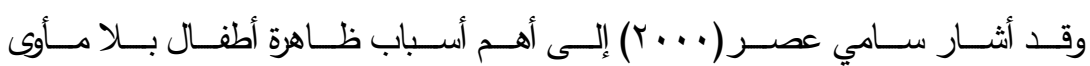

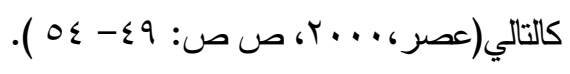

1- أسباب مجتمعية:- التسرب من التعليم- الهجرة من الريف الى الكينة- انتثار العشوائيات- الفقر الاعتماد على الأطفال وقيامهح ببعض الأعباء الأسرية.

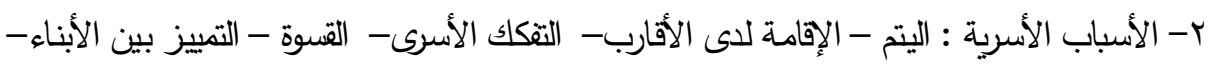

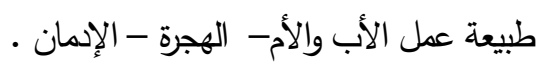
r- أسباب خاصة بالأطفال أنفهم : الميل إلى الحرية والهروب من الضغط والألوامر الأسرية - ضعف 


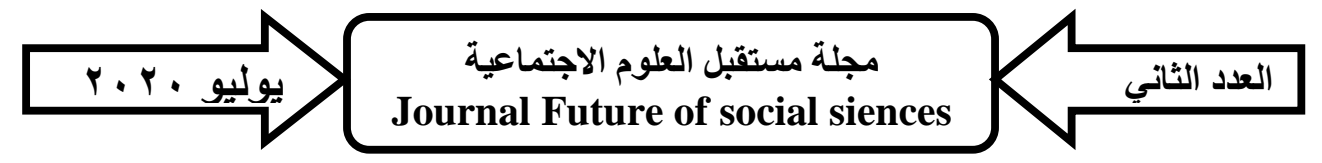

الرقابة من خلا لامبالاة الأسرة أو الثقة الزائدة منها- المحاكاة في السلوك لحالات أخرى في الأسرة أو لأحد الأبوين- حب التملك- عدم القدرة على التكيف مـع الظروف الأسرية غير المانئمة المنزة

ويمكن القول بأن هناك العديد من العوامل التي تتفاعل مـع بعضها بحيث تؤدى فى

النهاية الى خروج الطفل إلى الشارع، فلا يمكن النظر إلى هذه المشكلة من منظور أحادي لهاي بحيث نرجع خروج الطفل الى الثـارع الى سبب واحد. فالمشكلة متعددة الأطراف والعوامل

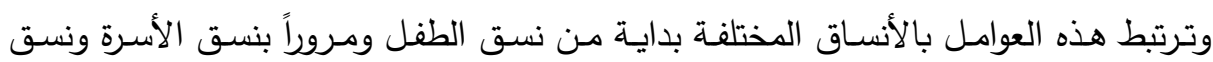
المدرسـة ونسق الشـارع ونسق المجتمع ككل.ويمكن توضيح تلك العوامل المتشـابكة والتي تم تحديدها من خلال الرجوع إلى الكتابات والأبحاث التى اهتمت بتحديد أسباب وعوامل وجود ظاهرة أطفال بلا مأوى من خلال الثكل التالي ( خليفة، ع . . ؟، ص 9 9 ) .

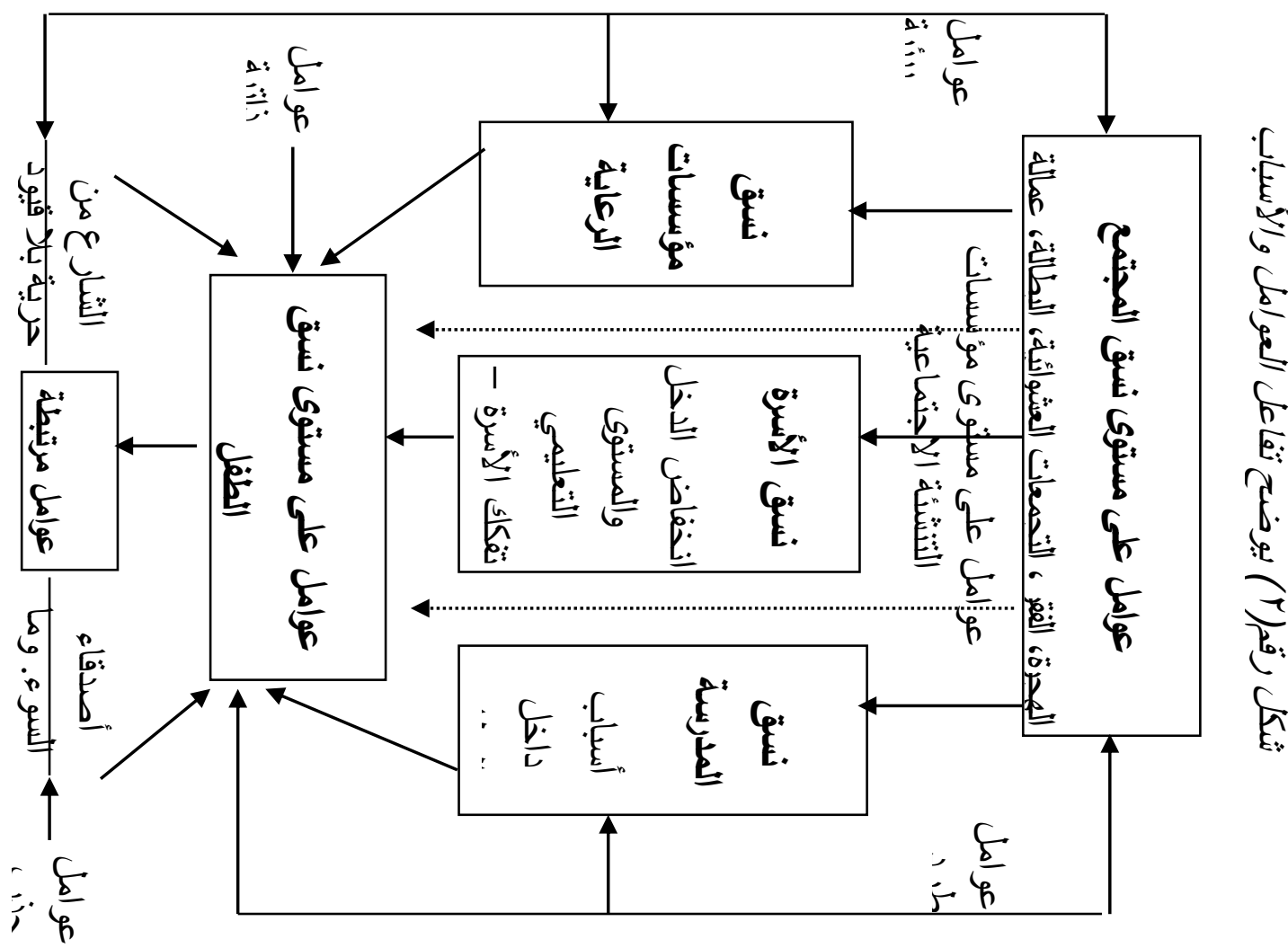

يتضح من شكل رقم (Y) تفاعل العوامل والأسباب التى أدت إلى وجود ظاهرة أطفال بلا مأوى ويتضـح ان هنالك العديد من الأنساق المختلفة التى ساهمت فى وجود الظاهرة ومن هنا فإن 


\section{بوليو · مجلة مستقبل العلوم الاجتماعية}

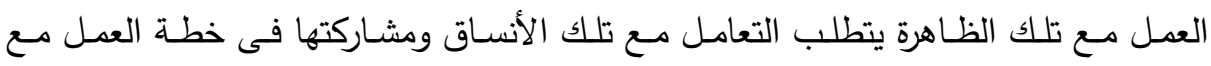
الأطفال وهذا يبين ويعكس لنا أن الأخصائى الاجتماعى يحتاج الى نموذج عمل يتيح لـه العمل مع تلك الأنساق

وتوجد العديد من الاحتياجات الاجتماعية لأطفال بـلا مأوى والتي يجب إثباعها

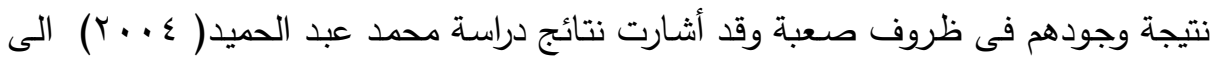
أن أهم هذه الاحتياجات: الحاجة الى تكوين العلاقات الاجتماعية - الحاجة إلى المشاركة فى

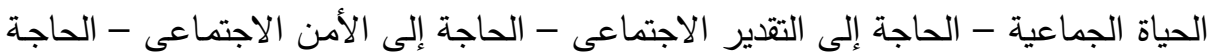

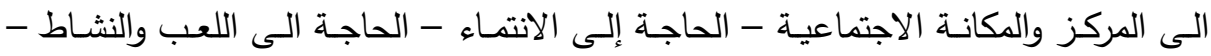

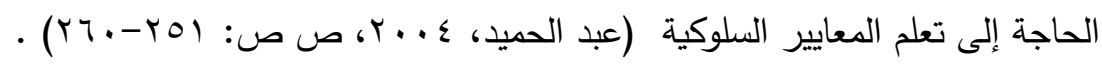

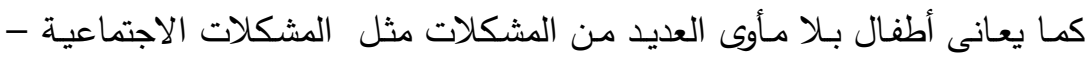
الاقتصادية -الصحية - المشكلات الحرفية - وكذلك توجد مشكلات الممارسة المهنية للخدمة الاجتماعية حيث لا يهتم الأخصائى الاجتماعى بتقوية العلاقة بين الأطفال والمنزل ، وعدم

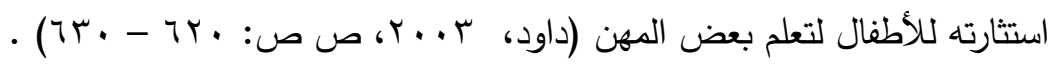

ويترتب على وجود مشكلة بحجم أطفال بلا مأوى إلى وجود العديد من التاثيرات

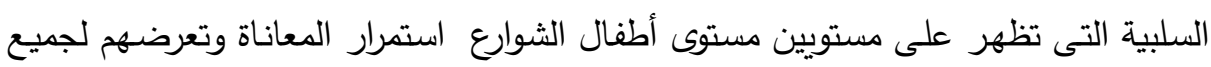

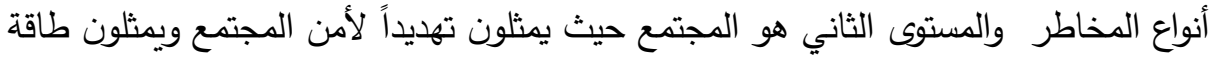

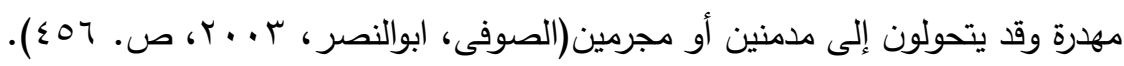
ويكتسب الطفل من وجوده في تلك الظروف بعض السمات العامة السلبية والتي منها الثغب والعناد والميول للعدوانية والانفعال الثديد والغيرة الثديدة والتمثيل والتشتت العاطفى

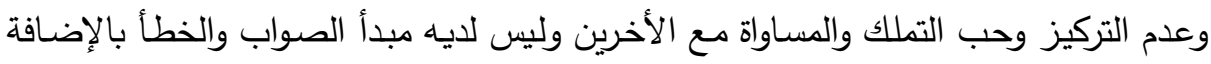

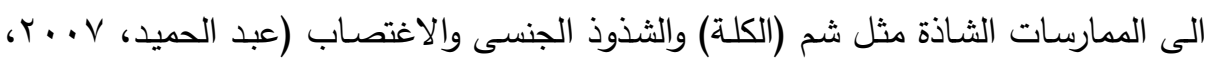

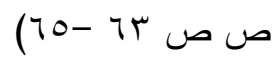

ومن خلال العرض السابق لأهم العوامل المسببة لظاهرة أطفال بلا مأوى والآثار المترتبة

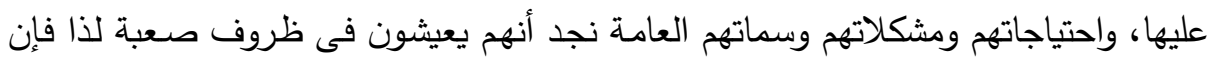

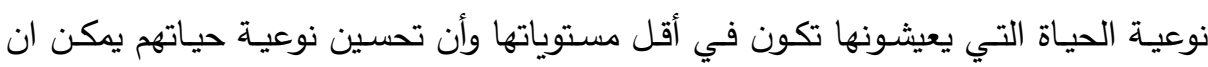

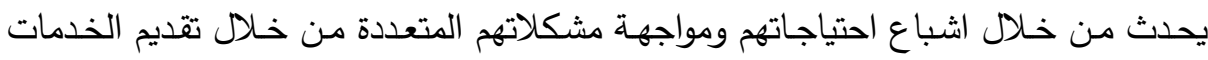




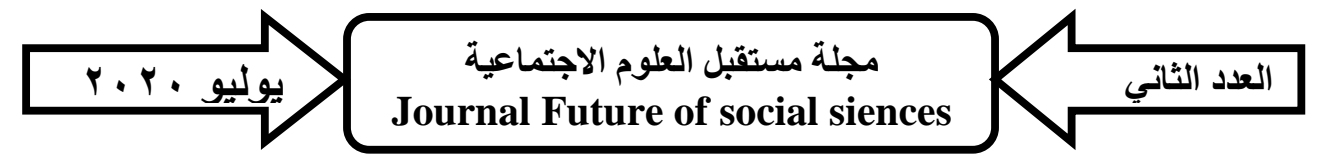

المختلفة لهم سواء كانت اجتماعية أو صحية او تعليمية أونفسية أو تاهيلية. ويعتبر تحسين نوعيـة الحياة مـن المفـاهيم المعاصـرة التي يستخدمها الأخصـائيون الاجتماعيون في ممارساتهم لتحسين نوعية الحياة وزيادة قيمتها ، فتشمل المحاولات لمساعدة الناس على المثابرة ومواصلة الحياة، وذلك بإضافة خبرات إيجابية وقيم لحياتهم المعيشية، ولا تشمل عملية تحسين نوعية الحياة فقط على العمل مـع المعاقين والمحرومين، ولكنها أيضـا متاحة لجميع الناس، وذلك بالتسليم بأن قد يواجه الأفراد مشكلات في علاقاتهم الإنسانية، وأيضـا لديهم المجال للنمو وتحسين قدراتهم وأنشطتهم في الحياة، فعملية الخدمة الاجتماعية لتحسين نوعيـة الحياة هي العملية التي يقوم بها الأخصـائيون الاجتمـاعيون لمسـاعدة الناس لتحسين علاقـاتهم بـالآخرين لتحقيتق مزيـد من الرضـا والإشـباعات في حياتهم ( السنهورى،

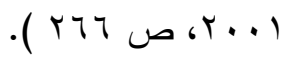

وللخدمة الاجتماعية مساهمتها الفاعلة من خلال دورها التتموي في تحسين نوعية الحياة وقياسـه والإرتقاء بمستوياته والارتقاء بمعدلات مؤشراته، وقد يكون ذلك الهدف الأول

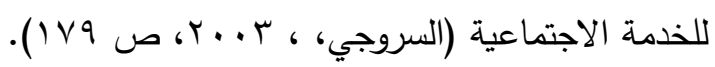

Rahman, Tauhidur et. al.,2003, P والثكل التالي يوضح مجالات نوعية الحياة

شكل (r) يوضح مجالات نوعية الحياة

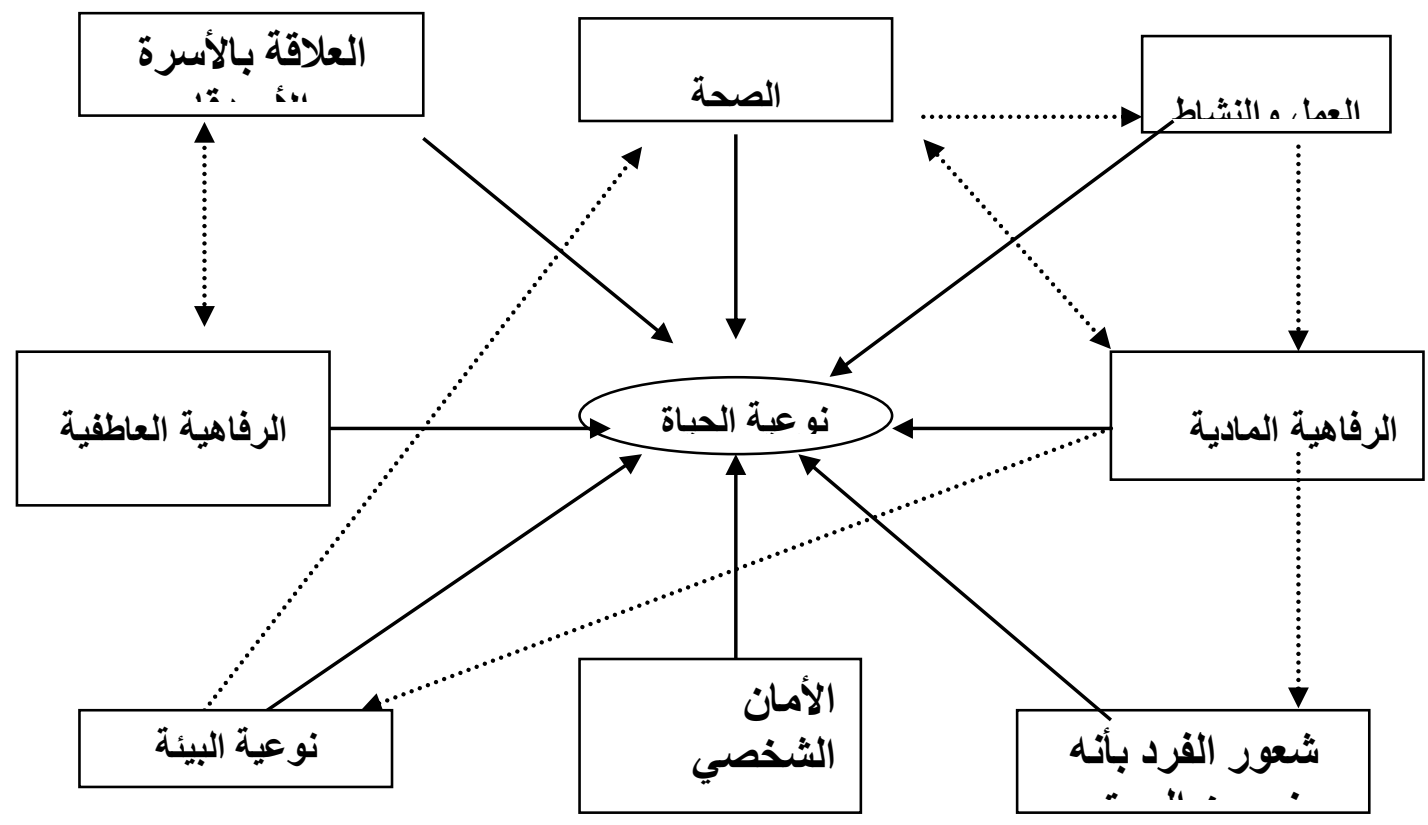




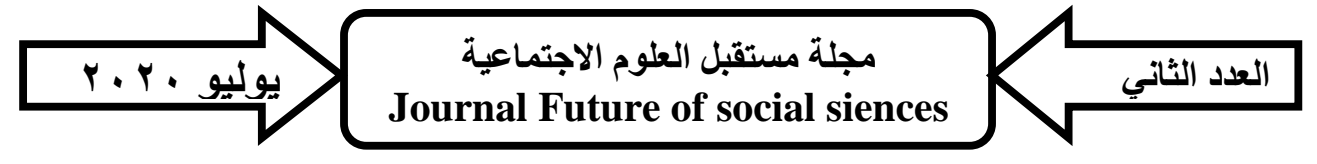

يوضـح شكل رقم (ץ) مجالات نوعية الحياة ، وإذا تم تطبيق تلك المجالات على

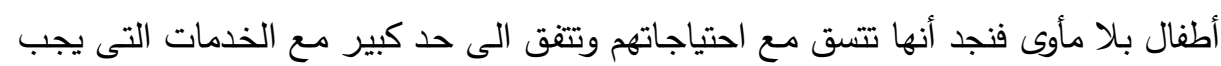

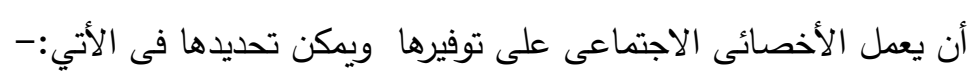

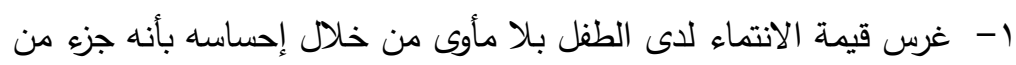

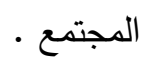

r- توفير الأمان الثخصي للطفل بلا مأوى. ץ- ب- تحسين علاقات الطفل بلا مأوى بأسرته وبأصدقائه.

ع- - توفير توازن عاطفى للطفل بلا مأوى.

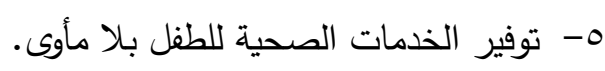

ولتحسين نوعية حياة أطفال بلا مأوى لابد من وجود أسلوب أو نموذج عمل يتيح

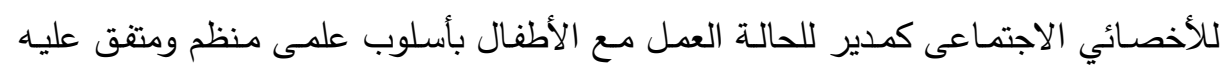

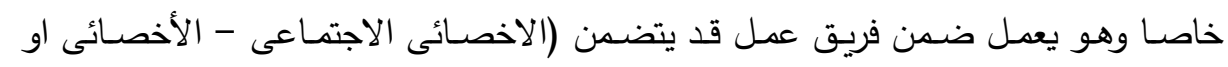

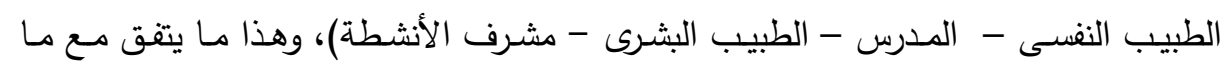

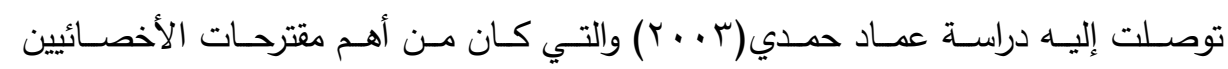

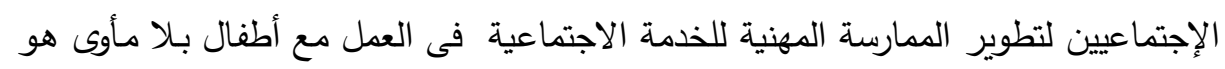

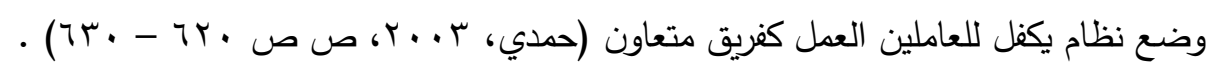
وبالتالى يمكن القول أن تحسين نوعية حياة الأطفال بلا مأوى عن طريق الأخصائي

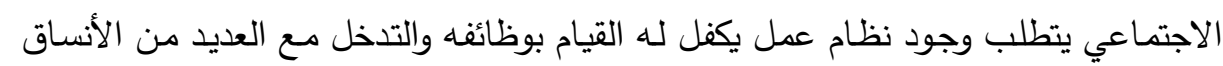
المرتبطة بالخدمات التي يجب ان تقدم للطفل ويمكن تحقيق ذلك من خلال إدارة الحالة.

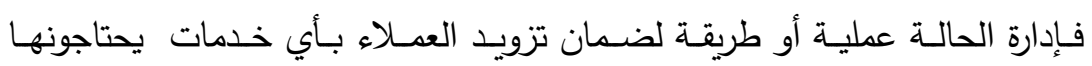

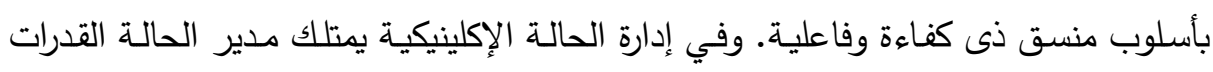

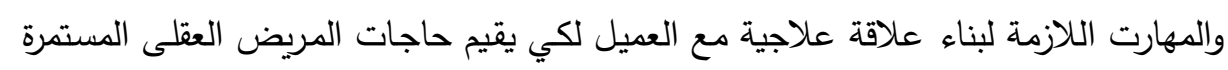

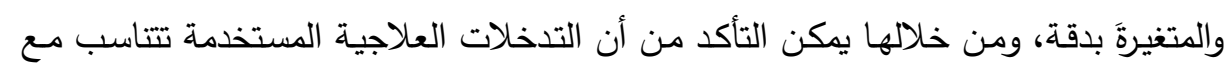

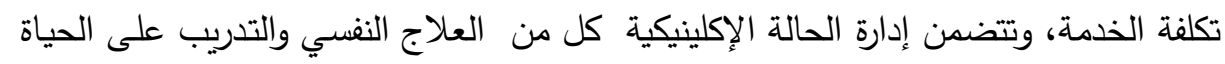

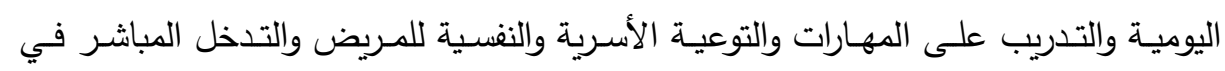

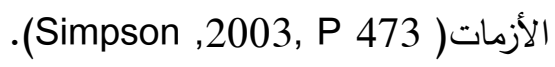




\section{العدد الثاني}

وقد استخدم مصطلح إدارة الحالة بشكل موسع لوصف الطريقة أو العملية التي يتم

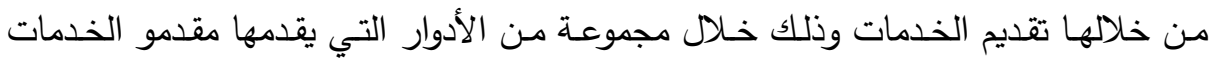
الصحية والاجتماعية ومنهم الأخصائيون الاجتماعيون ضمن فريق عمل فئل يضم مهنيين آخرين،

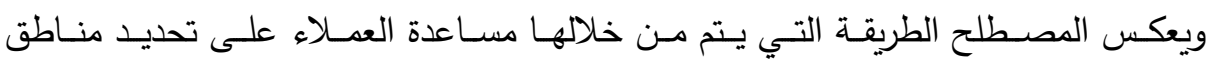

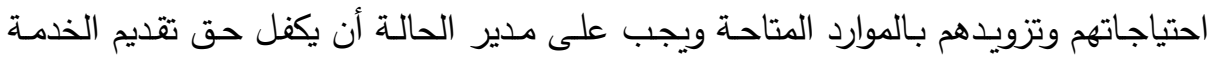

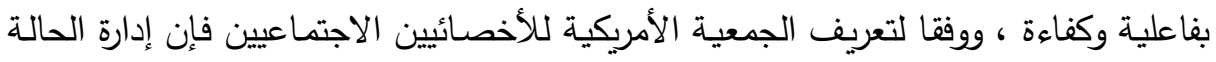

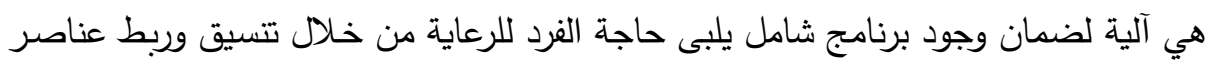

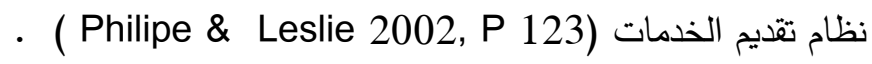

وقد عرفت إدارة الحالة في الخدمة الاجتماعية كوظيفة أساسية للخدمة الاجتماعية ، وأن

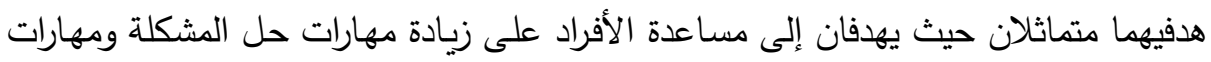

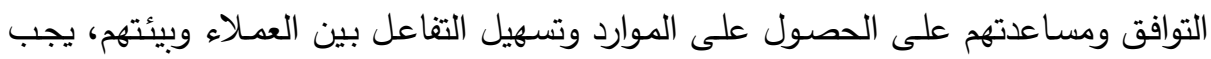
الإثارة إلى أن العملاء لا يتم ادارتهم إنما الخدمات هي التي تدار ، فمديرو الحالة يحتاجون إلى مهارات التدخل مع الأفراد والأسر والمؤسسات( K, Ashman2002, P 512) وتوجد علاقة واضحة بين وظائف إدارة الحالة ووظائف أخصائى خدمة الفرد حيث

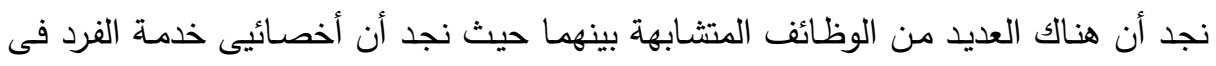

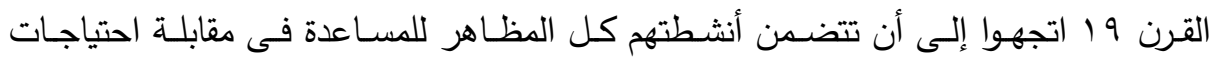

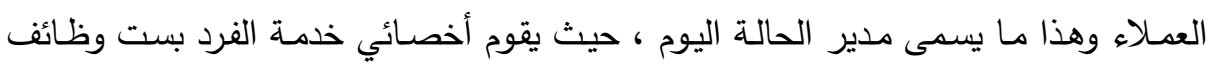

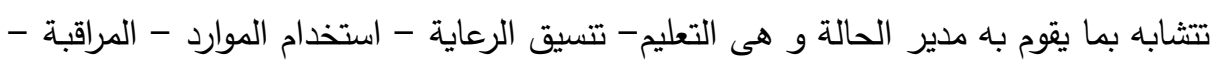

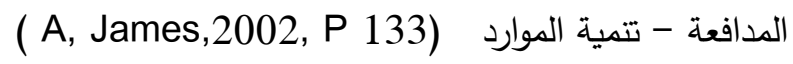

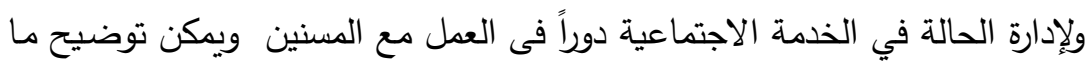
تحتويه التدخلات المهنية من خلال إدارة الحالة في الآتي: (Liu, 2004, P 5175) التعرف على مشكلات المسنين وتطوير خطط الرعاية. الإثراف على تقديم الخدمة للمسنين.

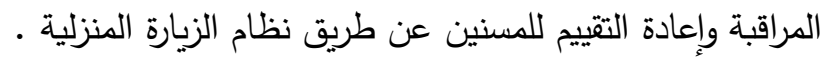
العلاج النفسى الاجتماعى والدعم العاطفى للمسنين. 


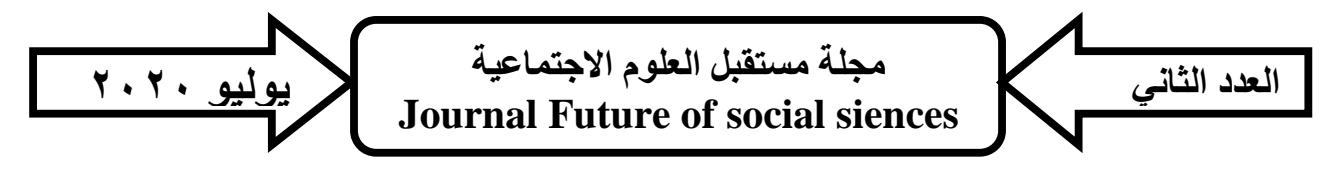

• تظيم جماعات الدعم المتبادلة للمسنين لكى تقوى شبكة العلاقات الاجتماعية وزيـادة

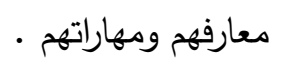

وتستخدم إدارة الحالة أيضا لتقديم الرعاية للطفل المريض فى المخ وإعادة تأهيله من

خلال ) ( Paediatric nursing, 2008, PP 24,25

- الدعم والنصيحة للطفل والأسرة .

- تزويد الطفل بالخدمات الضرورية.

- حضور اجتماعات فريق دراسة الجهاز العصبي الخاصة بالطفل.

- الاتصال بين المؤسسات المختلفة وتحديد إحتياجات الطفل.

- تتسيق الخدمات بين المؤسسات المختلفة.

- إيجاد الحلول المبتكرة.

- المراقبة المستمرة لتقدم الطفل والرعاية المقدمه له.

وتستخدم أيضا إدارة الحالة مع المرضى العقليين وهذا ما أظهرته نتائج دراسـة جاك

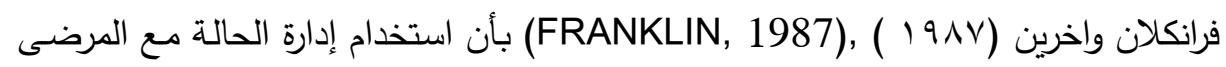

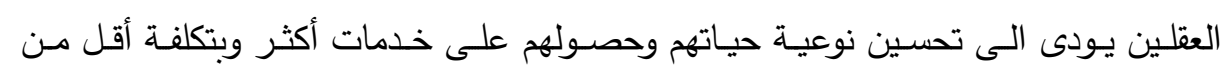

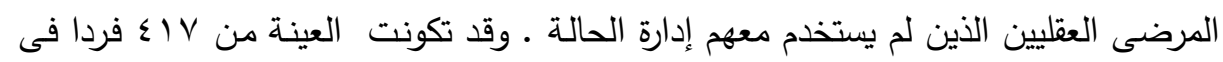
مستثفى الصحة العقلية وتم تقسيمهم الى جماعة تجريبية عددها (r T) مما تلقوا خدمات إدارة الحالة وجماعة ضابطة (ع • Y ) ممن تلقوا خدمات بدون استخدام إدارة الحالة. وقد تلقت الجماعة التجريبية خدمات أكثر بتكلفة اقل وتحسنت نوعيـة حياتهم وذلك لاستخدامهم إدارة الحالة على العكس من المجموعة الضـابطة التى تلقت الخدمات بأسلوب غير إدارة الحالة

.(FRANKLIN,1987, P 664,)

وكذلك استهدفت دراسـة(جاميس جودون واخرين) (Goodwin, 2003) تقويم

فاعلية استخدام الممرضـات لإدارة الحالة لتقديم الخدمات للمصـابات بسرطان الثدي واستخدم المـنهج التجريبـى بإسـتخدام جمـاعتين أحـدها ضـابطة وأخـرى تجريبيـة أعمـارهن 70 سـنة وتوصلت الدراسـة إلى أن استخدام إدارة الحالة يكون أكثر كفاءة وفاعلية فى تقديم الخدمات وتـوفير المـوارد، وكانــت النتـائج لصـالح المجموعـة التجريبيـة التـى اسـتخدمت معهــا إدارة

الحالة (Goodwin, 2003, PP 1251-1260) 


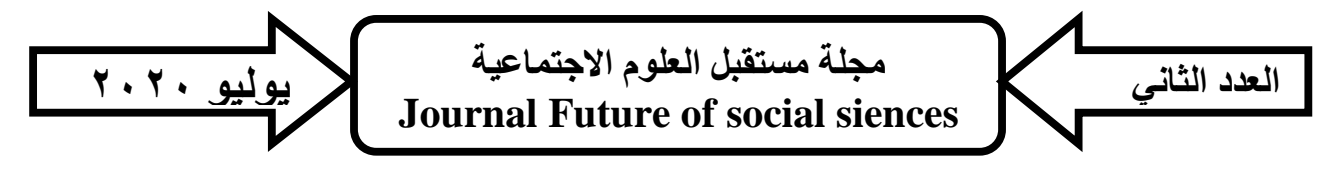

واستخدمت إدارة الحالة أيضـا مع الأطفال حيث استهافت دراسة لارين جانسون واخرين Jansson, Lauren, et.al, 2003 لتقديم الخدمات للأطفال الذين يعيشون مع أمهات يعتمدون على المخدر وكانت من أهم نتائج

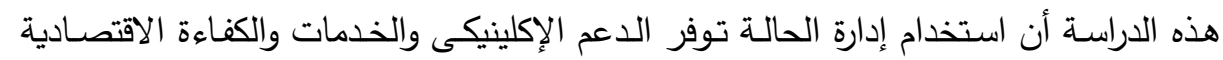
للطفل.

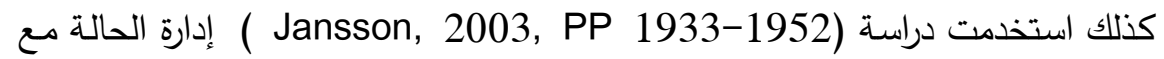
حالات الغشيان (فقد الوعى الحظى) حيث أثـارت إلى أن الخدمات المقدمة باستخدام إدارة

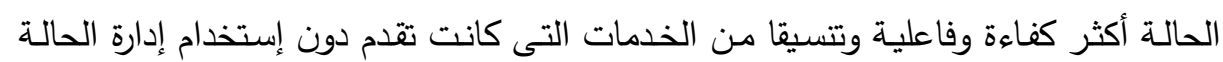

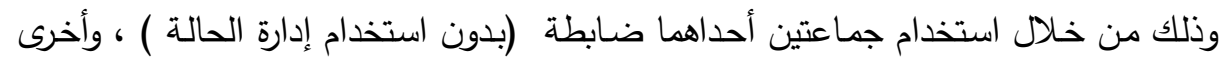

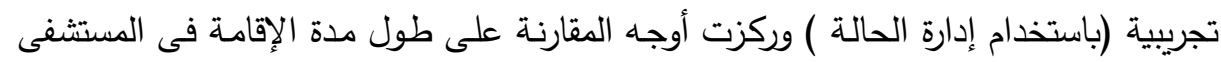
- تكلفة كل حالة - وكانت النتائج لصالح الجماعة التجريبية واستخدمت إستخدمت ايضا دراسة Bourdeaux, 2005 إدارة الحالة مع الأمهات المراهقات وأثبت فاعليتها فى تقديم خدمات أكثر كفاءة لهن (65- B, Bernadette 2005, PP 54).

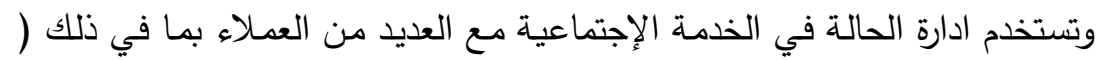

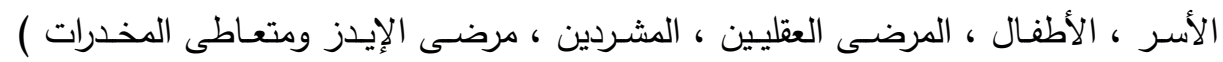
.( Compton, \& Galaway, 1999, P 367)

وهنـاك العديد من العوامل التى تؤثر على إدارة الحالـة وهذا مـا أوضـحته دراسـة

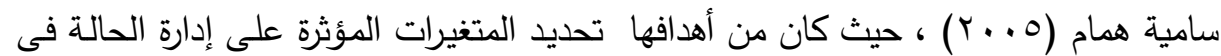
المجال الطبي وأثارت إلى أن هناك متغيرات مرتبطة بأخصائى خدمة الفرد (الإعداد المعرفى الهى

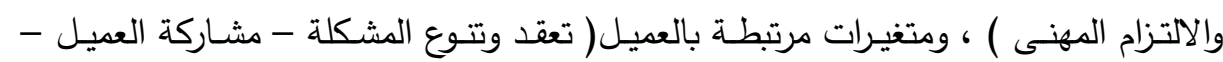

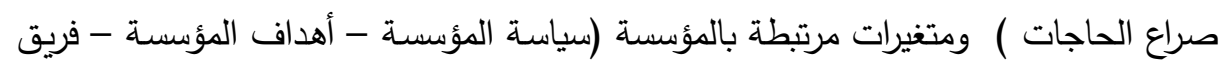

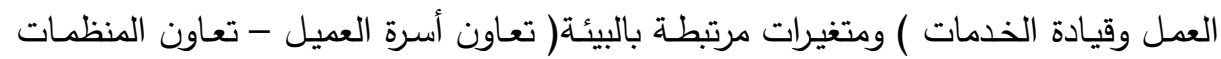

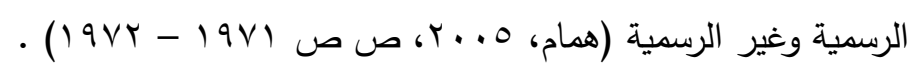

وإذا نظرنا إلى تلك المتغيرات نجد أنها قاسم مشترك توثر على فاعلية إدارة الحالة

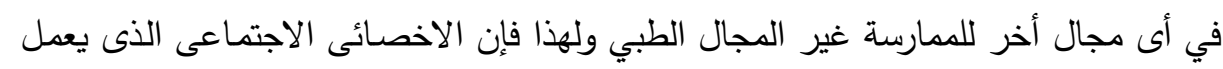




\section{بوليو · مجلة مستقبل العلوم الاجتماعية}

مـع أطفال بـلا مأوى مستخدما إدارة الحالة قد تؤثر عليه تلك المتغيرات والتي تمثل أنساق يتعين التعامل معها لتحقيق أهداف ادارة الحالة من أجل مصلحة الطفل.

وهناك العديد من الجمعيات التي تعمل في مجال أطفال بـلا مأوى ولا تهتم برامج

وأنشطة الغالبية العظمى لهذه الجمعيات بالعمل على مستوى المجتمع، ولكن ينصب تهن تركيزها

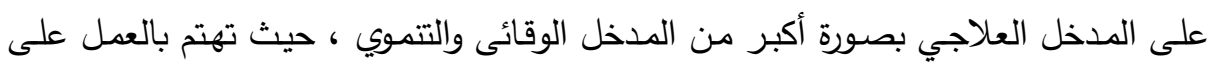

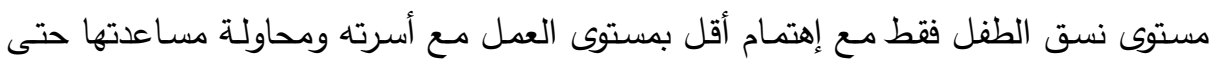

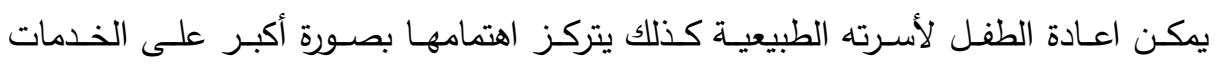

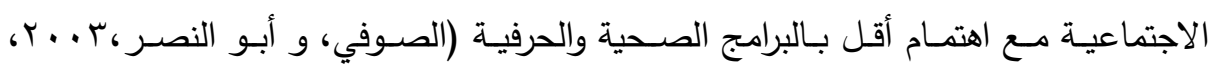

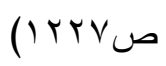

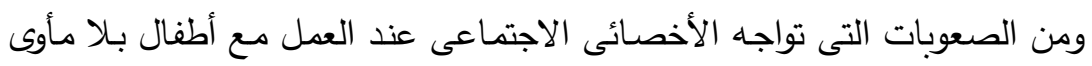

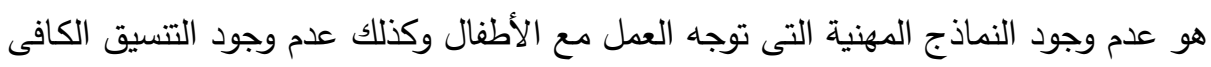

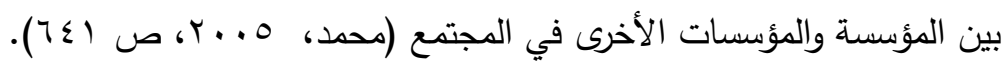

ومن ثم يكون بناء نموذج لإدارة الحالة للتعامل مـع أطفال بلا مأوى ذا أهمية في

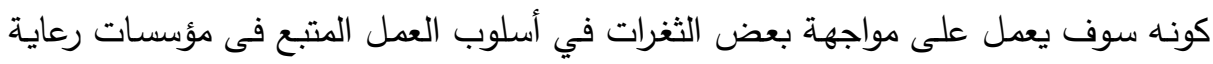

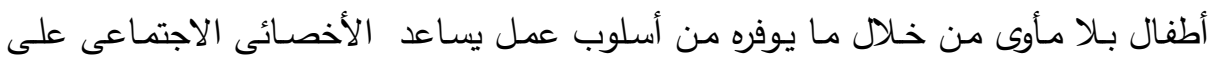

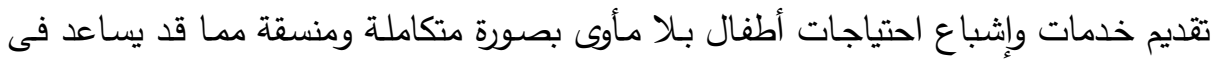
تحسين نوعية حياة الأطفال .

وتتدر المحاولات العربية لبناء نموذج لإدارة الحالـة فى المجالات المختلفة ومنها

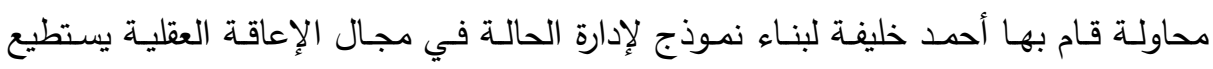

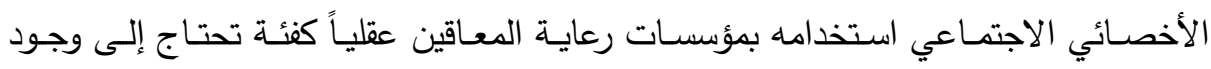

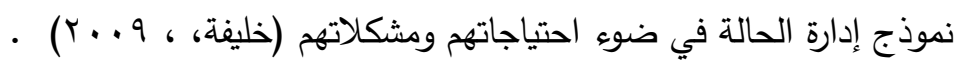

ومن خلال العرض السابق نجد أن الأخصائى الاجتماعى الذي يتعامل مع أطفال

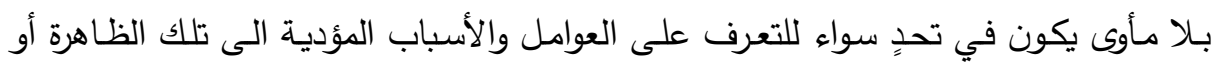

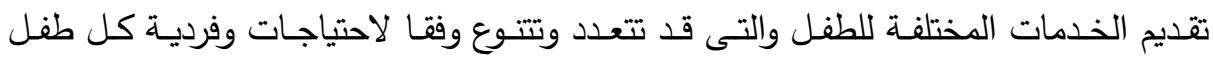
وظروف المؤسسة التى يعمل بها التى تتطلب الاتصـال بالعديد من المؤسسات المهتمة بتقديم 


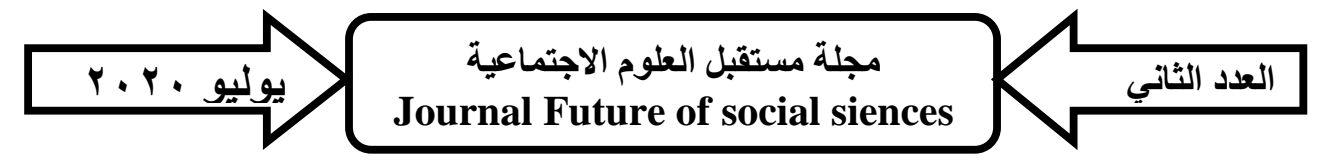

الخدمات والرعاية الى الطفل سواء كانت (خدمات تعليمية - صحية - تدربيية - مهنية نفسية - اجتماعية بالإضـافة إلى عمله مـع أسرته للعمل على عودة الطفل إلى أسرته مرة - أخرى)

ولهذا فان تقسير الظاهرة وكذلك التعامل معها يحتاج العمل مع العديد من الأنساق والتي تستلزم التتسيق والتقاوض والتعاون والمدافعة والتذخل مع مختلف تلك الأنساق من أجل مصلحة أطفال بلا مأوى وهذا ما تتطلبه إدارة الحالة بصفة عامة، لذا فإن الدراسة الحالية

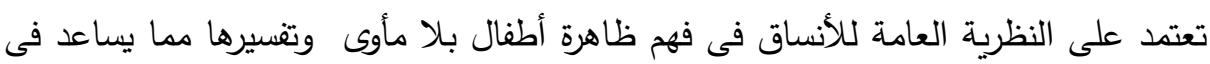
بناء نموذج لإدارة الحالة يتمشى مع طبيعة وخصائص ومشكلات واحتياجات أطفال بلا مأوى

وتزودنا نظرية الأنساق العامة بمجموعة من المفاهيم التى تساعد على تفهم وتحليل طبيعة التفاعل بين الفرد والأنساق المختلفة ، وكذلك فى تحليل هذه الأنساق والتعرف على مكوناتها مما يؤدى إلى تحديد الخلل فى هذه الأنساق وعملية التقاعل بين الأفراد والأنساق وهاق

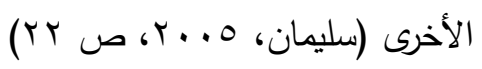

وتعتمد النظرية العامة للأنساق على ثلاث ركائز أساسية وهى (عثمان، عبد الفتاح

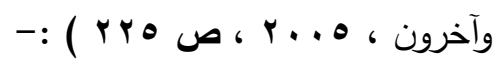

1- ثـة علاقات تبادلية بين كافة الظواهر الإنسانية فى إطار الحدود الخارجية للنسق. كما أن ثـة علاقات تحكم علاقة النسق نفسـه بكافة الأنساق المحيطة تزداد اتساقا بتقارب هذه الأنساق وتقل بتباعدها. ץ- لا يمكن فهم أى ظاهرة جزئية إلا فى إطلار الكل الثمولي للنسق أو الأنساق التى ترتبط بها. r- لكل نسق نزعة تلقائية للتوازن الذاتي homeostasis بهن 


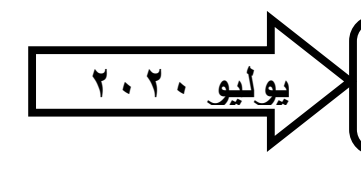

مجلة مستقبل العلوم الاجتماعية
Journal Future of social siences

ثانياً: مشكلة الدراسة

بناء على المعطيات السابقة يمكن القول :- - يواجه أطفال بلاء مأوى العديد من المشكلات والاحتياجات المتعددة سواء كانت (اجتماعية

$$
\text { - صحية - نفسية - مهنية - تعليمية - اقتصادية). }
$$

- قد يؤدى إشباع تلك الاحتياجات إلى تحسين نوعية حياتهم.

- -

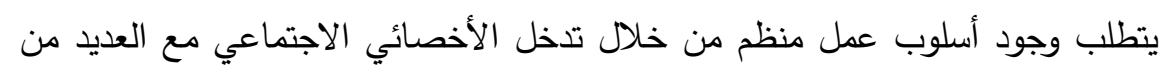

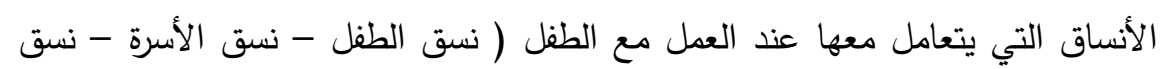

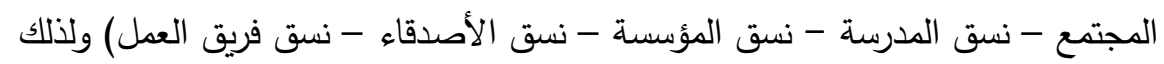
تتطلق الدراسة من النظرية العامة للأنساق.

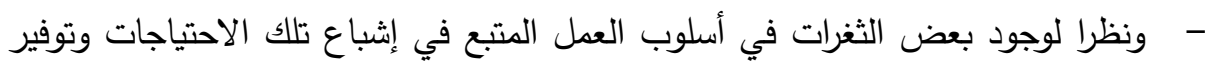

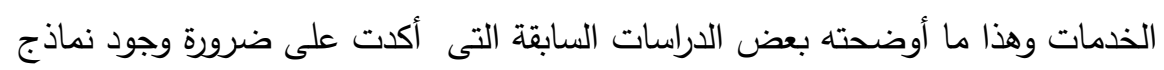

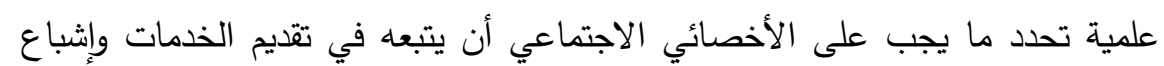

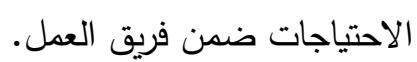

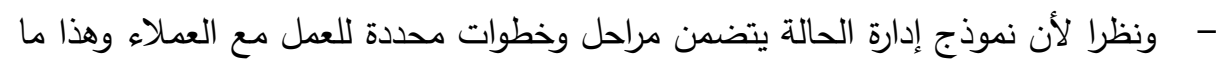
تم توضيحه سابقا فإن الباحث يحاول بناء نموذج لإدارة الحالة يساعد الأخصائي

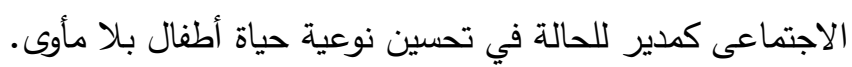

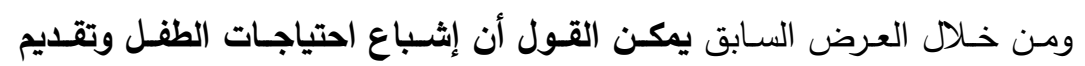

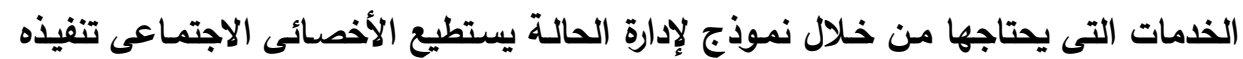

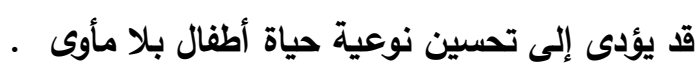

وفى ضوء ذلك تتحدد قضية الاراسـة فى تساؤل رئيسي مؤداه مـا نموذج إدارة

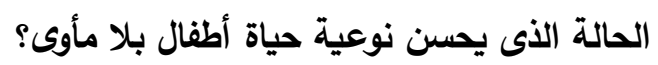

ثالثاً: أهمية الدراسة.

1 - يمثل أطفال بـلا مأوى طاقة مهدرة تهدد استقرار وأمن المجتمع ومـا يسببونه من

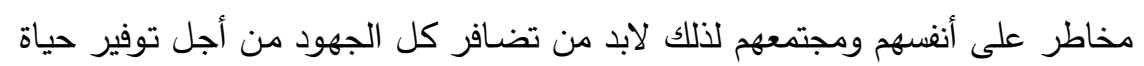

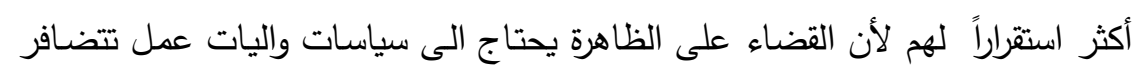
بها كل مؤسسات الدولة، حيث يقدر الجهاز المركزي للتعبئة والإحصاء عام (Y... (Y) 


\section{بوليو · مجلة مستقبل العلوم الاجتماعية}

عدد الأطفال بـلا مأوي حوالي (r) مليون طفل وهذا ما تم تسجيله في مراكز رعاية

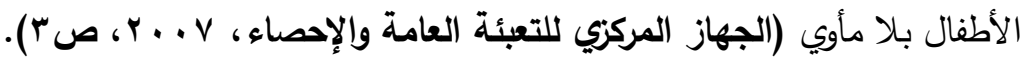

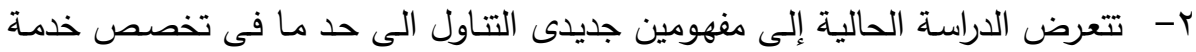
الفرد وذلك فى حدود علم الباحث وهما (إدارة الحالة - تحسين نوعية الحياة).

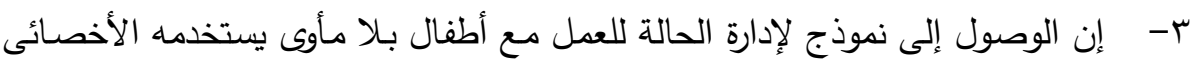

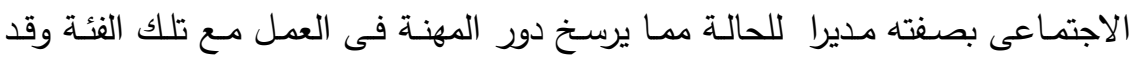

يواجه بعض الثغرات في أسلوب العمل المتبع مع تلك الفئة. رابعاً:أهداف الدراسة. 1- بناء نموذج لإدارة الحالة لتحسين نوعية حياة أطفال بلا مأوى.

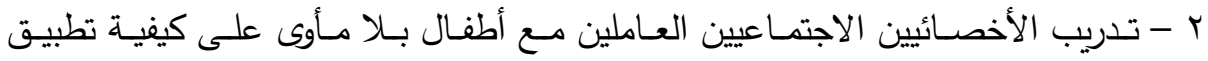

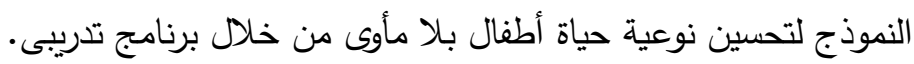

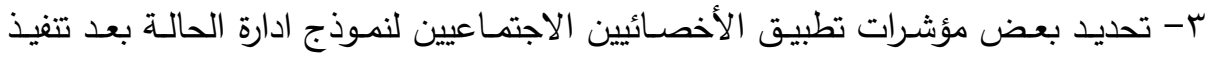
خامساً :مفاهيم الدراسة : التبرئى (1) مفهوم نمـوذج إدارة الحالـة: يعرف النموذج العلمي بأنه نموذج لتتظيم أفكارنـا حول

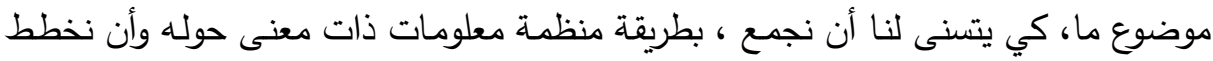

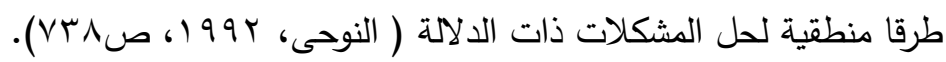
كما أنه إطار فرضي لعلاقات متداخلة بين ظواهر نظريـة معينة ، ولكن في مجال

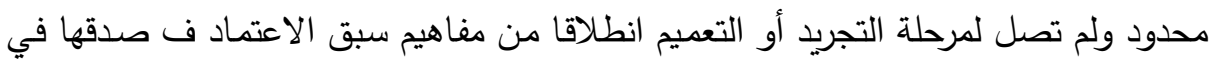

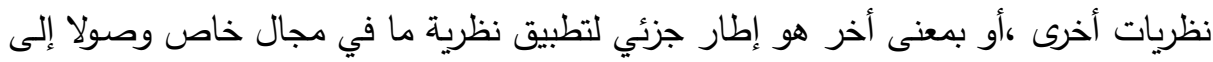

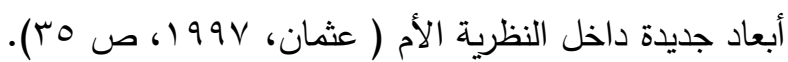

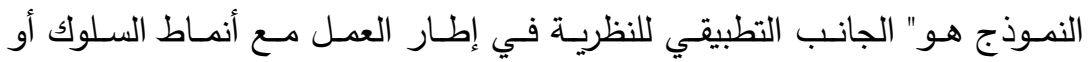

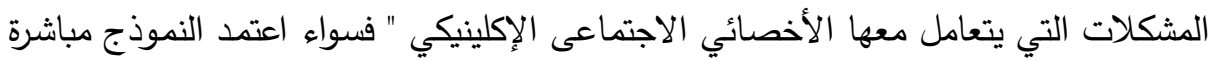

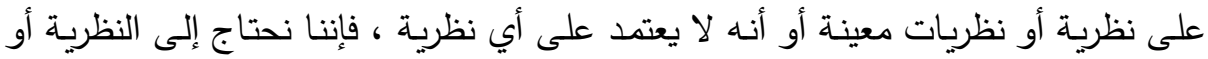

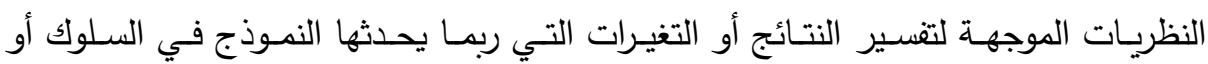

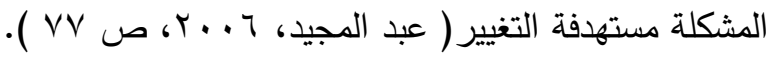




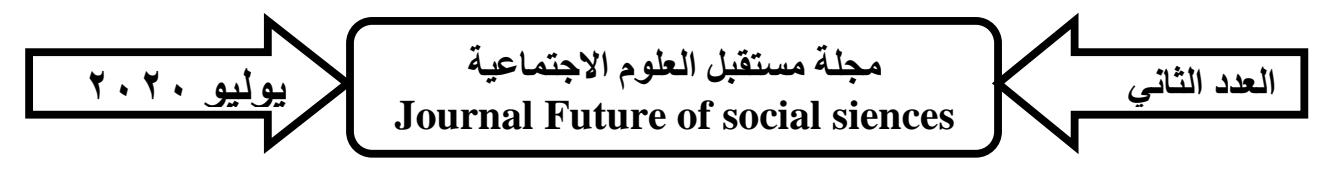

مفهـوم إدارة الحالـة: عرف بـاركر Barker إدارة الحالـة على أنها إجـراء للتخطيط ومراقبـة الخدمات بين مختلف المؤسسـات الاجتماعيـة والعـاملين مـن أجـل مصـلحة العميل، وعـادة تتحمل مؤسسة واحدة المسئولية تجاه العميل وتعين مديراً للحالة ينسق الخدمات ويدافع عن العملاء وفى بعض الأحيان يتحكم فى الموارد وتلك الإجراءات يمكن أن يقوم بها الأخصائيون R. L, Barker, الإجتماعيون فى المؤسسات الإجتماعية من خلال فريق العمل المهني .$(1999$, P 62)

وإدارة الحالـة عمليـة تعاونيـة تتضـمن التقييخ، التخطيط، التتفيذ، المراقبة، التسسيق، وتقيم الخيـارات والخدماتَ المطلوبـة لمقابلـة الحاجـاتَ الصـحية للأفراد واسـتخدام عمليـات

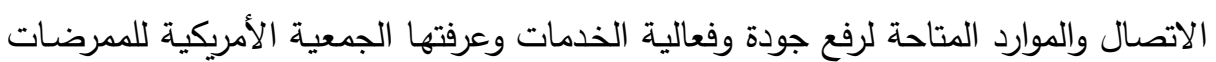
(1991 ( ) بأنـه نظام لتوصـيل الرعايـة الصـحية صـم لتَسهيل تحقيق النتائج المتوقعـة لتكون ملائمـة خـلال فترة الإقامـة، وانـه نمـوذج للممارسـة يستخدم مـدخل منهجي للتعريـف المحدد fundamentals of ( ) للمرضسى وإدارة رعايـة المرضـى ليضـمن لهم نتائج مثاليـة .(tuberculosis case management,2008, p 2

عرف ( اتحاد المستشفيات الأمريكية ) إدارة الحالة بانها عمليـة تخطيط وتتظيم وتتسـيق ومراقبـة الخــدمات والمــوارد المطلوبــة للاسـتجابة لاحتياجـات الرعايــة الصــحية والاجتماعية (Compton, \& Galaway 1999, P 367). فإدارة الحالة عبارة عن مجموعة من الخطوات والعمليات المنطقية التي تتفاعل ضمن شبكة من الخدمات تؤدي إلى تقديم الخدمات التي يحتاجها العميل ل لمساندته بأسلوب كفء وفعال (Gursansky ,2003, P 67) ) عرفت الجمعية الأمريكية إدارة الحالة:-

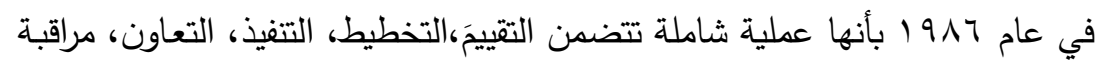
الجودة،وتقييم الخدمةِ لتحديد مستوى رضا المريض بالرعاية الصحية المقدمة، ويجب

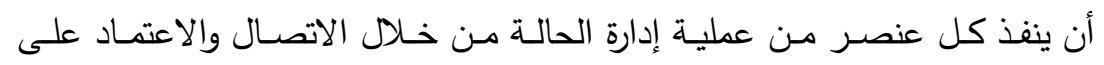
Chi-ChiLu, الموارد لتحقيق أعلى مستوى من جودة الرعايـة وبأكثر فاعليـة . (2007, P 70 


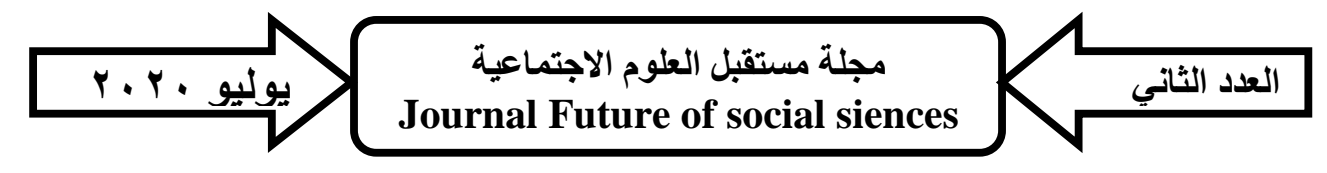

وفى عام ^ . . r عرفت بأنها عملية تعاونية من التقييم، التخطيط، التسهيل ودعم

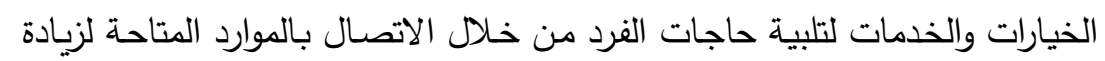
فاعلية وجودة الخدمة (2009,P 2 De Man, ).

وقد وصفت بأنها التخطيط والتتسيق لتسهيل الرعايـة وتوجيه المرضى وأسرهم خـلال الرعاية (Weis 1999, P 254) بوفن ).

ويمكن تعريفها على أنها عملية تعاونيـة تتضمن التقدير - التخطيط - التسهيل

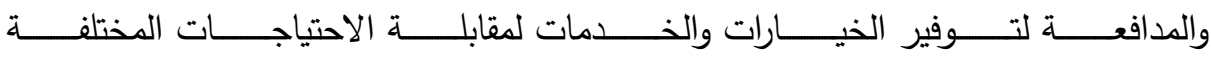
•للعميل (Bourdeaux, ,2005, P 141)

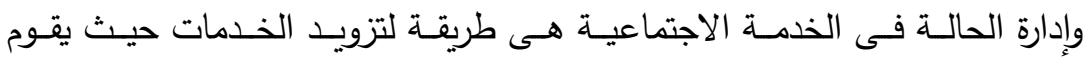

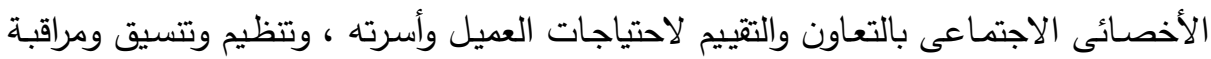

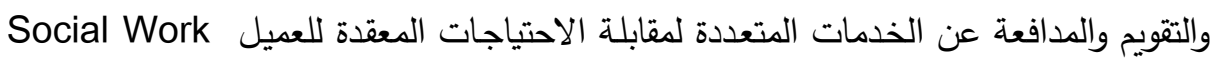
(Best Practice Healthcare Case Management Standards ,2005, P 2 ) وإدارة الحالة فى خدمة الفرد هى عبارة عن أسلوب مهنى أو مجموعة من الأساليب

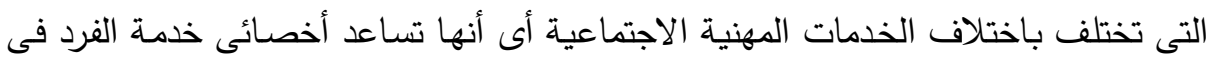

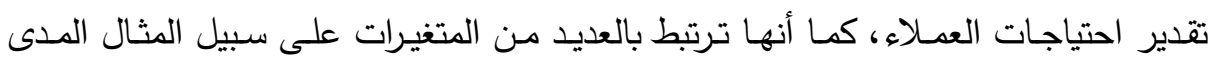

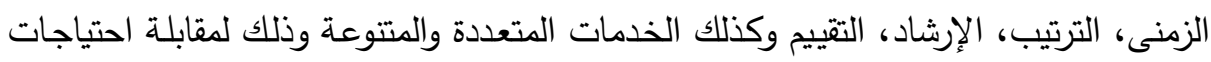

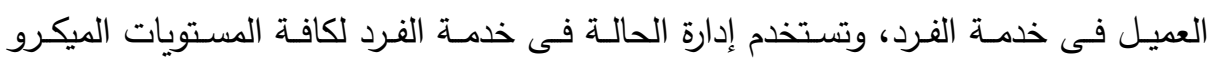

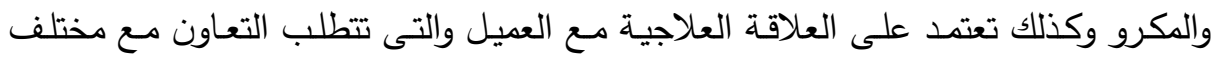

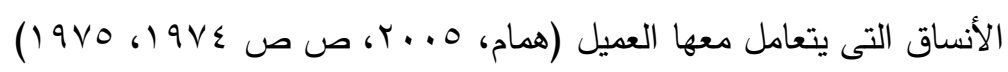
إدارة الحالة هي سلسلة من الأنثطة التي تهدف إلى ربط نسق الخدمة بالعميل وتتسيق مكونات النسق لتحقيق نتائج ناجحة (DFK Wong, 2009, P 12)

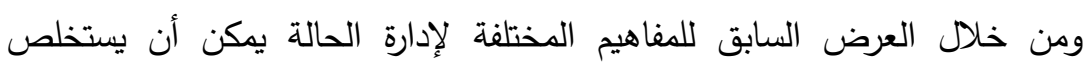

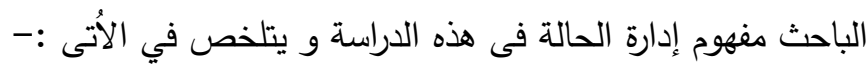

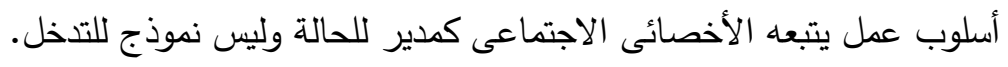




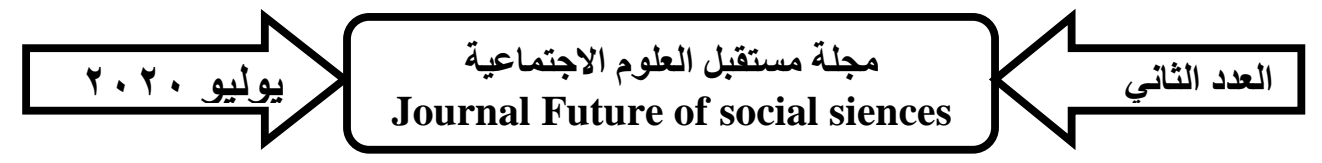

مجموعـة مـن الخطـوات التـي تتضـمن مجموعـة مـن الأنشـة للتنظيم والتتسيق والمدافعة وتوصيل الخدمات للأطفال بلا مأوى بأقل تكلفة وبأعلى جودة من التطبة خلال إتباع مجموعة من الخطوات.

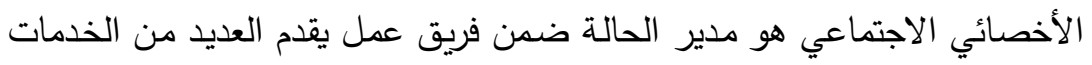
ويلتزم بالعديد من القيم والمبادى المهنية.

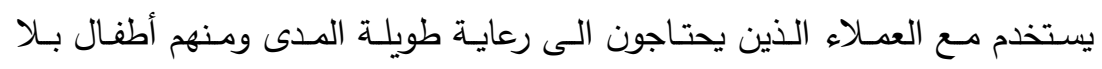
مأوى . هناك العديد من العوامل التى تؤثر على إدارة الحالة ومنها عوامل مرتبطة بمدير الحالة وبالمؤسسة وبالبيئة المحيطة وبغريق العمل .

ومن خلال العرض السابق لمفاهيم النموذج وخطوات بنائه وكذلك مفهوم إدارة الحالة

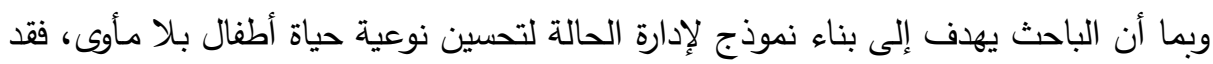

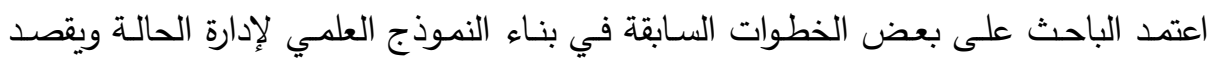

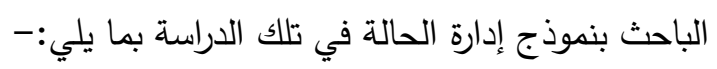

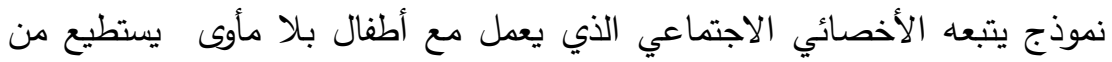

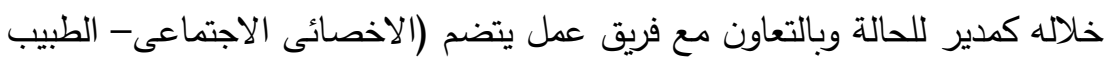

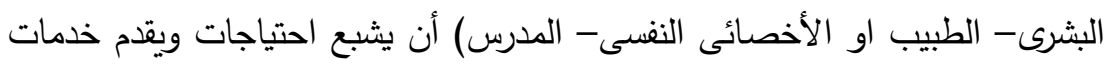

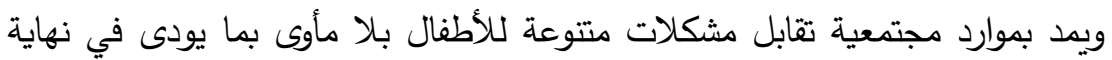
إتباع خطوات النموذج إلى الوصول إلى درجة مقبولة من تحسين مندئ نوعية حياتهم. يتكون هذا النموذج من مجموعة من المراحل والخطوات المتسلسلة .

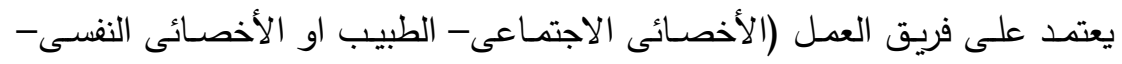
الطبيب البشرى - المدرس). يقوم الأخصائى كمدير للحالة بمجموعة من الوظائف (التقدير - التخطيط- التتفيذ-

$$
\text { التقويح- الانهاء - المتابعة ). }
$$

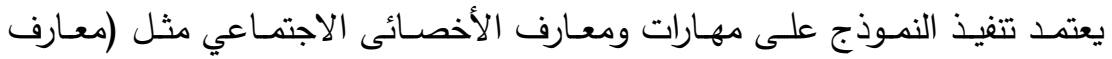

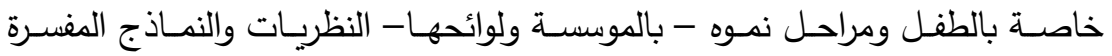

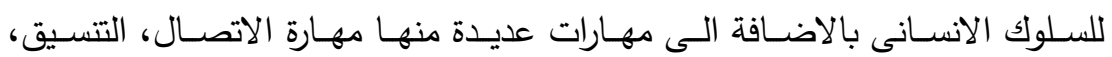
المدافعة، اتخاذ القرار ، التفاوض). 


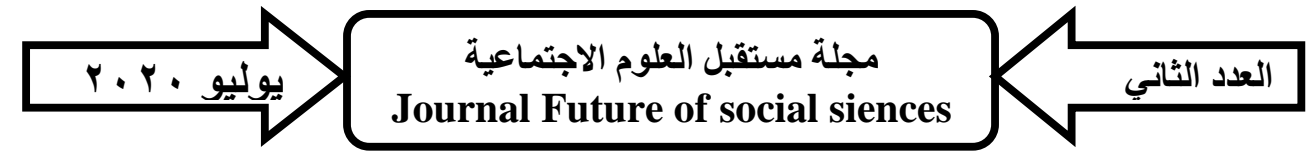

يستخدم مجموعـة مـن التكنيكات العلميـة وفقـا للنمـاذج العلميـة التـى قد يستخدمها

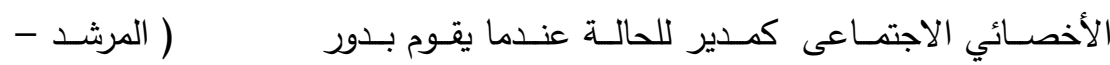

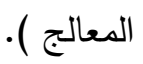

• ونظرا لعدم وجود مسمى وظيفى لمدير الحالة فى مؤسسات رعاية أطفال بلا مأوى لذا

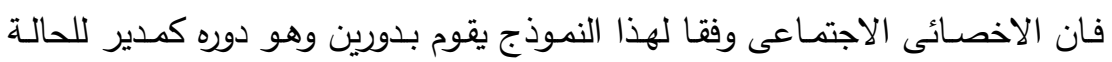

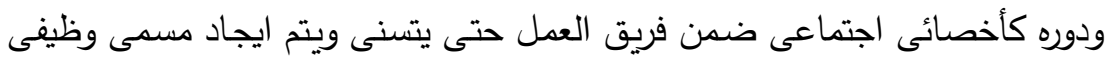

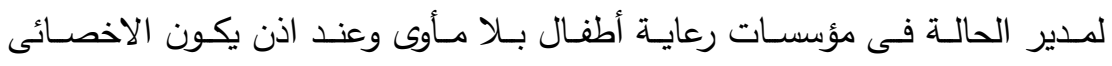

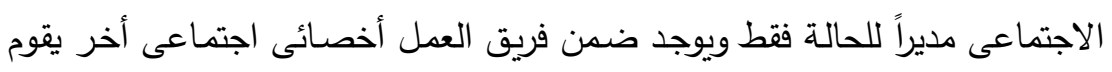

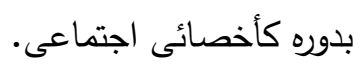

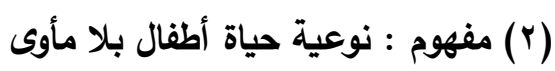

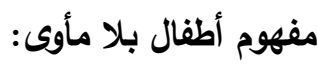
طفل بلا مأوى : كل طفل (ذكر أو أنثى) عمره أقل من 1 أسنة يعيش وينام ويأكل ويلعب

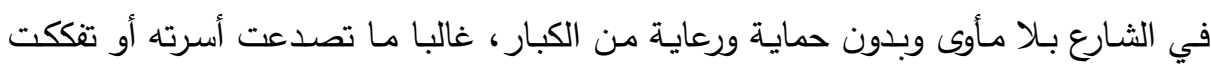

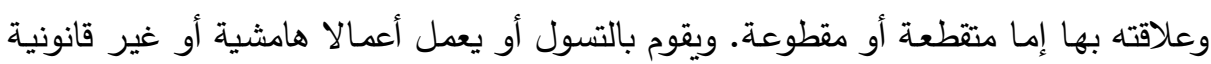

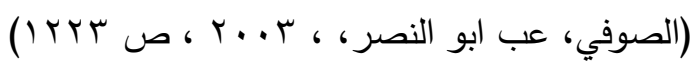

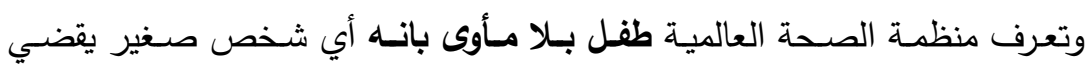

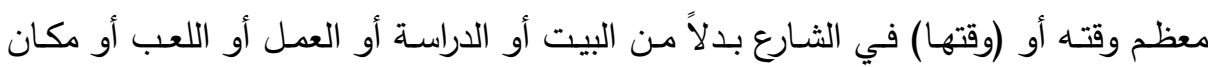

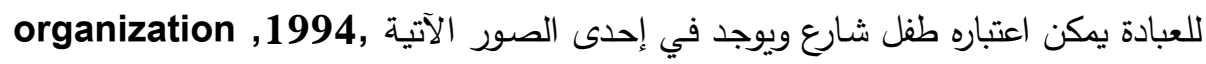
- :(world health P 21) 1- من يعيشون في الثارع ومشغولين بسبل البقاء وإيجاد المأوى، وربما تخلت عنهم أسرهم،

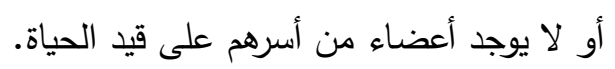
r- المنفصلين عن أسرهم ويتحركون من صديق لاخر أو يلجأون إلى المباني المهجورة أو أو

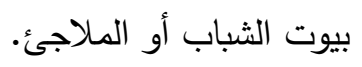
r- الأطفال الذين يبقون على اتصالهم بعائلاتهم ولكن يقضون معظم أيامهم وبعض لياليهح

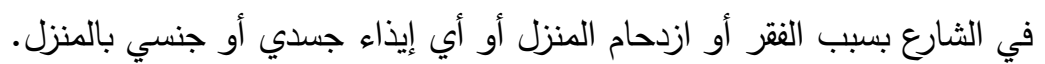

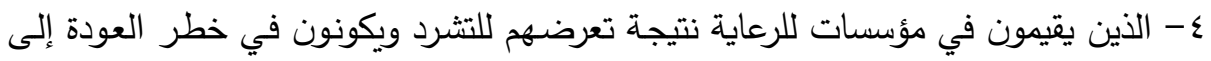
حياة التشرد. 


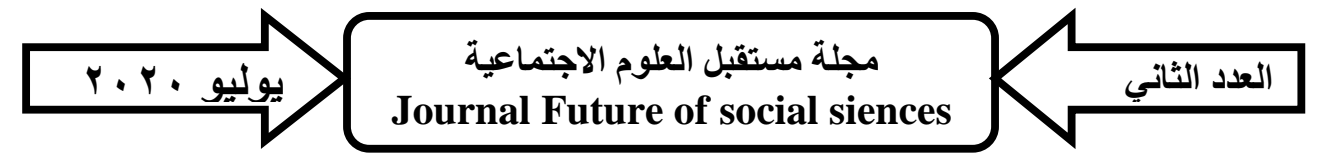

طفل بلا مأوى هو كل طفل من أسرة تصدعت وتفككت ويعانى من ضغوط نفسية

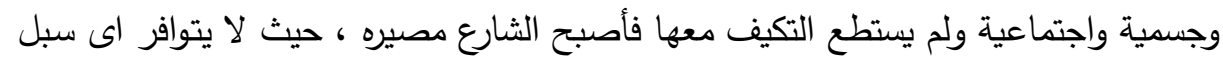

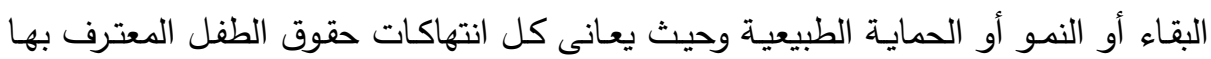

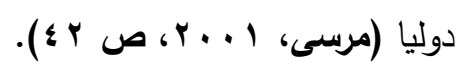

يذهب بعض العاملين في حقل رعاية الطفولة إلى التمييز بين فئتين من أطفال بـا

$$
\text { مأوى ( صلاح، V... r، ص r r). }
$$

الأولى : الأطفال الذين يعيشون في الثارع أي الذين يتصف وجودهم في الثارع بالاستمرارية

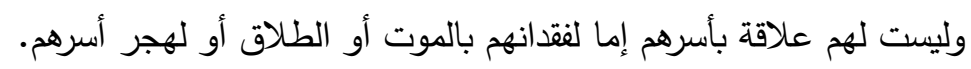

الثانية : الأطفال الذين يعيشون فى الثارع الذين يمارسون مهن هامشية في الثارع ولكنهم في

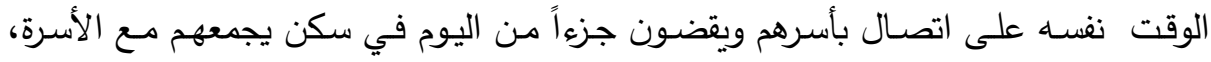
وأطفال اتصالهم ضعيف بأسرهم يذهبون إليهم كل حين.

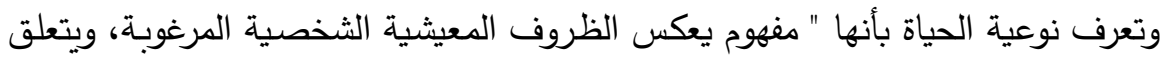

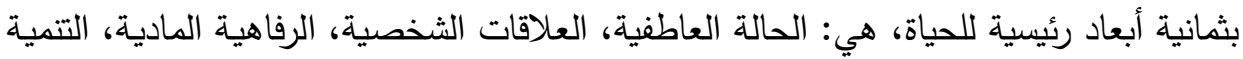

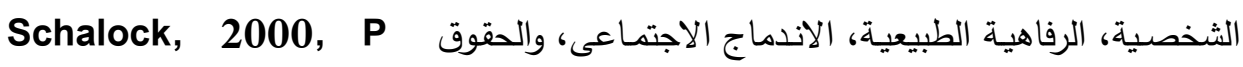

كما تعرف نوعية الحياة بأنها" مفهوم متعدد الأبعاد في التركيب(البناء) يشمل الدكونات

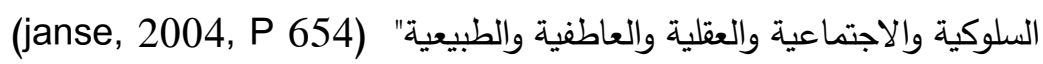

كما تعرف نوعية الحياة بأنها " مقياس لقدرة الأفراد على العمل جسديا، عاطفيا واجتماعيا

داخل بيئاتهم في مستوى يتقق مع توقعاتهم) (Church, 2004, P 15)

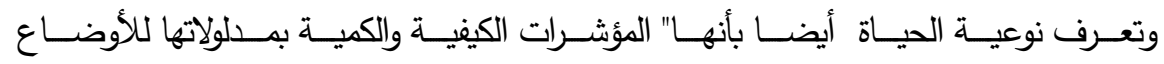

والظروف الاجتماعيـة والصحية والاقتصـادية والتفاعل بين هذه الظروف وانعكاساتها علـي درجـة

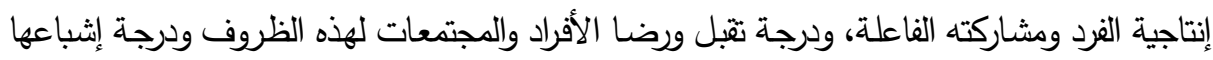

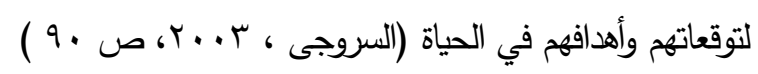

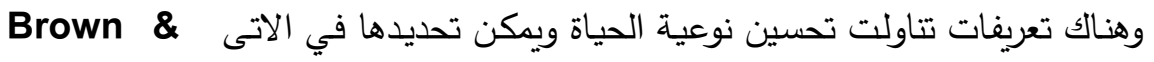

$$
\text { -: (Browen 2003, P 101) }
$$

1- هي الحالة الاجتماعية التي يتمتع بها الناس، الفئات ومجتمعهم. 


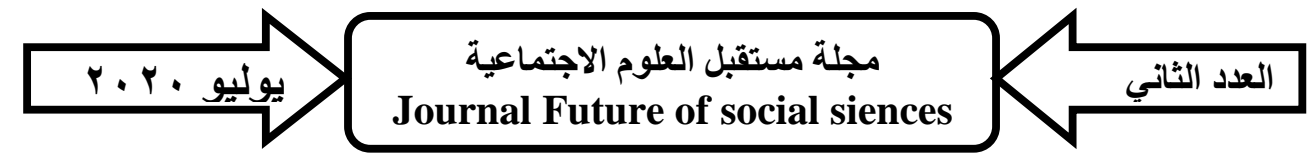

r- تتضمن كلا من الأبعاد الموضوعية والثخصية ، يتضمنان الحالة المادية ، الصحة ، معدل الإنتاج ، الألفة ، الأمان والحالة العاطفية.

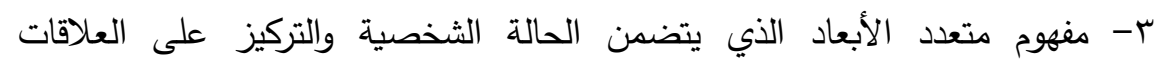
الاجتماعية، الحياة العائلية، الصداقات، مستوى المعيشة، العمل، لالة السكان

$$
\text { والإسكان والتعليم والصحة. }
$$

ـ- عند مقابلة الحاجات الأساسية للفرد وعندما يتاح الفرصة أمام الأفراد للسعي وتحقيق والفيق

$$
\text { الأهداف الأساسية في حياتهم. }
$$

0- عندما يكون الأفراد لديهم القدرة على مقابلة الحاجات الأساسية في حياتهم ( العمل - المدرسة - البيت - المجتمع ) التي يجب أن تشبع تطلعاتهم وتحقق لهم مستوى الترات

$$
\text { عالي من نوعية الحياة. }
$$

7- التأكيد على تشجيع التعبير عن المشاعرِ، وتوفير فرص للإنجاز والشعور بعلاقة

$$
\text { اجتماعية إيجابية. }
$$

V- تمثل الدرجة التي يثبع بها الفرد حاجاته لكي يدعم ذات متوافقة مع نفسها ومع

$$
\text { البيئة الاجتماعية. }
$$

ويمكن تحديد العناصر الأساسية لتحسين نوعية الحياة للأطفال بلا مأوى في هذه

الدراسة في ضوء مجالات نوعية الحياة وما يعانية اطفال بلا مأوى من مشكلات

$$
\text { واحتياجات فى الأتي : }
$$

1- تحسين علاقات الطفل الاجتماعية مع أسرته وزملائه . r- المساعدة فى تسهيل توفير وتقديم الرعاية الصحية للطفل .

r- المساعدة فى توفير فرص التعليم للطفل . ع- تحسين تقدير الطفل لذاته. 


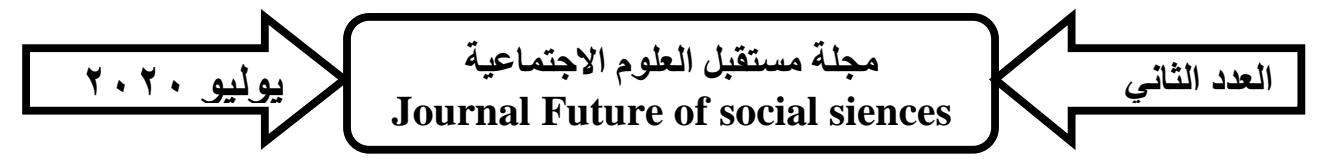

سادسا: النتائج العامة للاراسة:-

يود الباحث قبل عرض النتائج العامة للدراسة أن يثير إلى أن نتائج تلك الدراسة لا يمكن

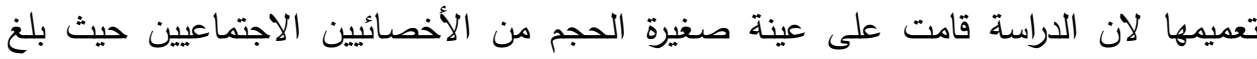

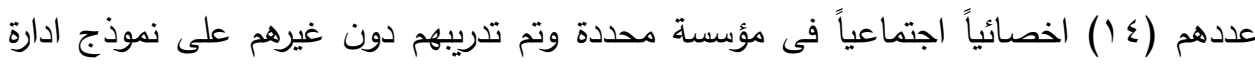

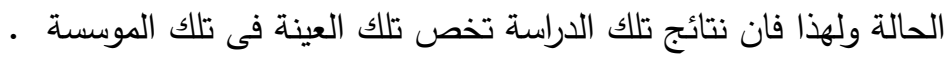
وكان من أولى نتائج هذه الدراسة هو بناء نموذج لادارة الحالة لتحسين نوعية حياة

$$
\text { أطفال بلا مأوى حيث كانت محتويات النموذج كالأتي: }
$$

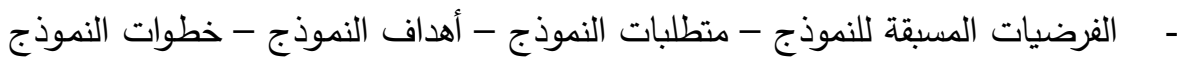

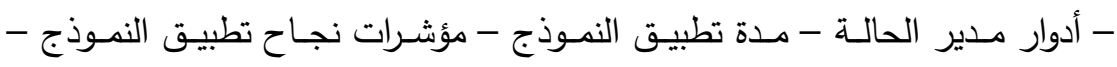

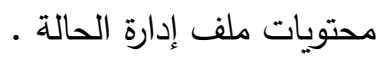

أ : النتائج الخاصة بالفرض الرئيسى الاول للدراسة:

ينص الفرض الرئيسى الاول لهذه الدراسة على الأتى:

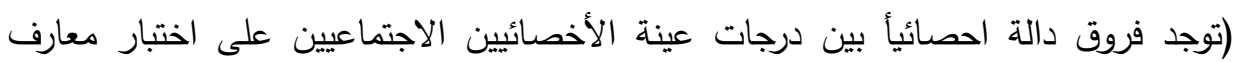

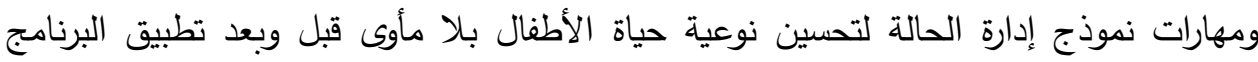

وتم التحقق من صحة هذا الفرض من خلال قياس زيادة معارف ومهارات عينة الدراسة من الأخصائيين الاجتماعيين بعد تطبيق البرنامج التدربيى المرتبطة بالابعاد الأتية :

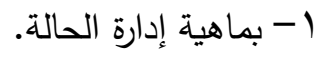

r- برحلة التقدير في نموذج إدارة الحالة.

r- مرحلة التخطيط للخدمة والعلاج في نموذج إدارة الحالة .

ع - مرحلة تتفيذ خطة العمل فى نموذج إدارة الحالة .

0- مرحلة التقييم المستمر وإعادة التقدير في نموذج إدارة الحالة.

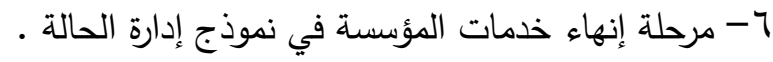

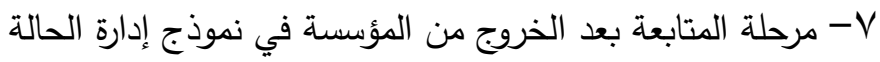

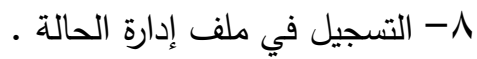




\section{بوليو · مجلة مستقبل العلوم الاجتماعية}

ويعتبر التحقق من من صحة الفروض الفرعية اشارة الى التحقق من صحة الفرض

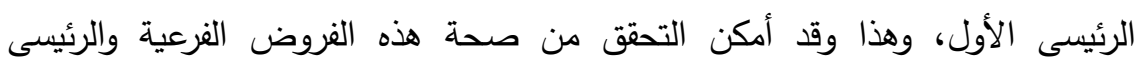

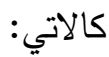

1 - الفـرض الفرعسى الاول: توجد فروق دالـة احصـائياً بـين درجـات عينـة الأخصـائيين الاجتماعيين على اختبار معارف ومهارات نموذج إدارة الحالة لتحسين نوعية حياة الأطفال

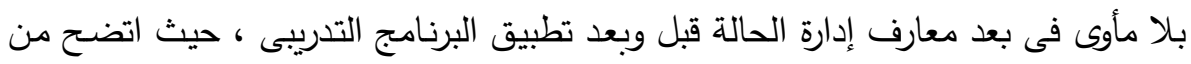

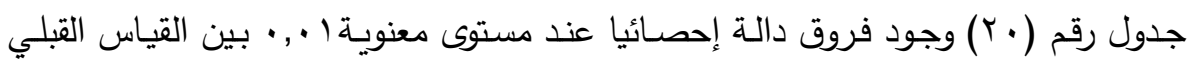

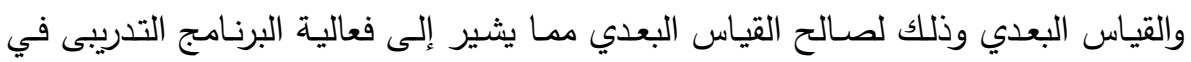
زيادة معارف عينة الدراسة من الأخصائيين الاجتماعيين الخاصة بما هية بإدارة الحالة.

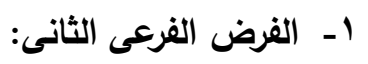

توجد فروق دالة احصائياً بين درجات عينة الأخصائيين الاجتماعيين على اختبار

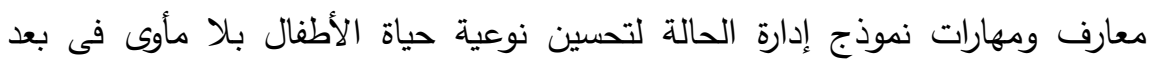
معارف ومهارات مرحلة التقدير قبل وبعد تطبيق البرنامج التدريبى، حيث اتضح من

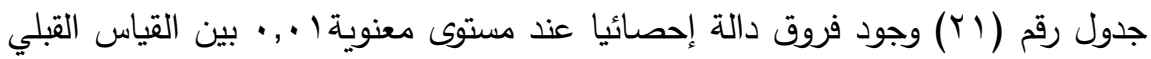
والقياس البعدي وذلك لصالح القياس البعدي مما يشير إلى فعالية البرنامج التدريبى في دئي

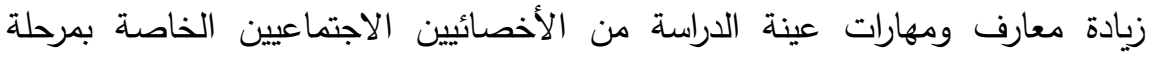

$$
\text { r- التقدير في إدارة الحالة. }
$$

توجد فروق دالة احصائياً بين درجات عينة الأخصائيين الاجتماعيين على اختبار

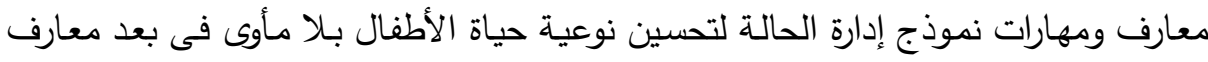

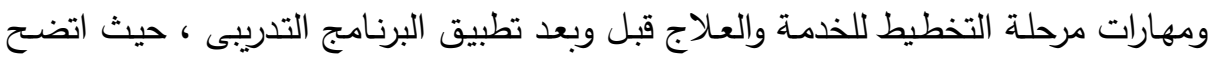
من جدول رقم (Yr) وجود فروق دالة إحصائيا عند مستوى معنوية ا ., • بين القياس القبلي

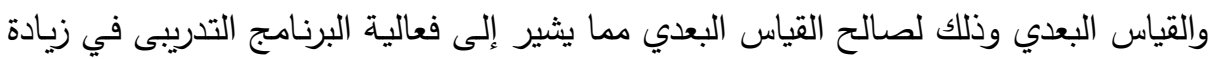
معارف ومهارات عينة الدراسة من الأخصائيين الاجتماعيين الخاصة بمرحلة التخطيط للخدمة

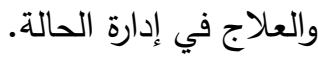




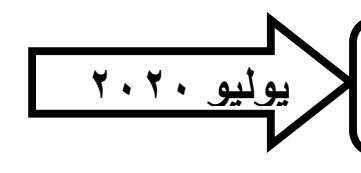

\section{مجلة مستقبل العوم الاجتماعية Journal Future of social siences}

العدد الثاني

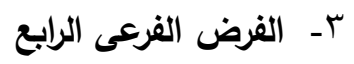

توجد فروق دالة إحصائيأ بين درجات عينة الأخصائيين الاجتماعيين على اختبار

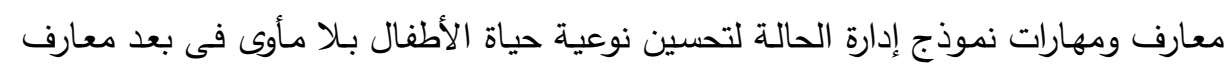
ومهارات مرحلة تنفيذ خطة العمل قبل وبعد تطبيق البرنامج التدربيى ، حيث اتضح من جدول

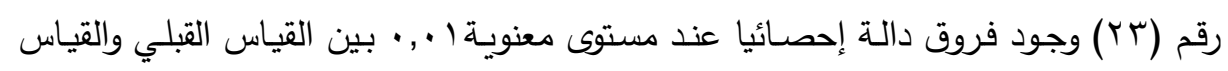
البعدي وذلك لصالح القياس البعدي مما يشير إلى فعالية البرنامج التدريبى في زيادة معارف ومهارات عينة الدراسة من الأخصائيين الاجتماعيين الخاصـة بمرحلة تنفيذ خطة العمل بإدارة

الحالة.

ع- - الفرض الفرعى الخامس

توجد فروق دالة إحصائيأ بين درجات عينة الأخصائيين الاجتماعيين على اختبار

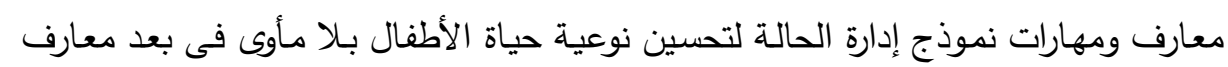

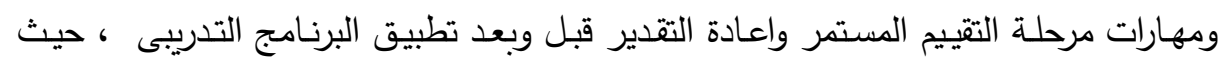

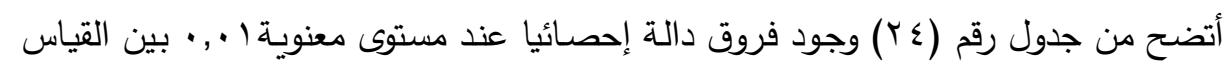
القبلي والقياس البعدي وذلك لصالح القياس البعدي مما يشير إلى فعالية البرنامج التدربيى في زيـادة معارف ومهارات عينـة الدراسـة من الأخصـائيين الاجتمـاعيين الخاصـة بمرحلـة التقييم المستمر وإعادة التقدير في إدارة الحالة. 0- الفرض الفرعى السادس

توجد فروق دالـة إحصـائيأ بـين درجـات عينـة الأخصـائيين الاجتمـاعيين على

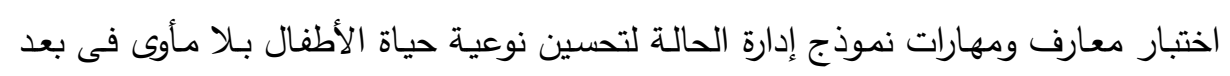

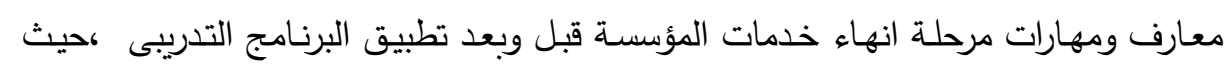
اتضح من جدول رقم ( T ) وجود فروق دالة إحصائيا عند مستوى معنوية ا ., · بين القياس القبلي والقياس البعدي وذلك لصالح القياس البعدي مما يشير إلى فعالية البرنامج التدريبى في إني زيـادة معـارف ومهارات عينـة الدراسـة مـن الأخصـائيين الاجتمـاعيين الخاصــة بمرحلـة إنهاء خدمات المؤسسة في إدارة الحالة. ד- - الفرض الفرعى السابع.

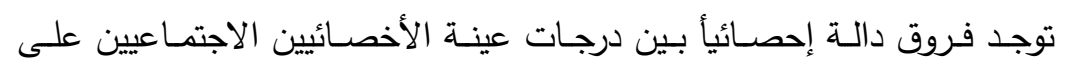
اختبار معارف ومهارات نموذج إدارة الحالة لتحسين نوعية حياة الأطفال بـلا مأوى فى بعد 


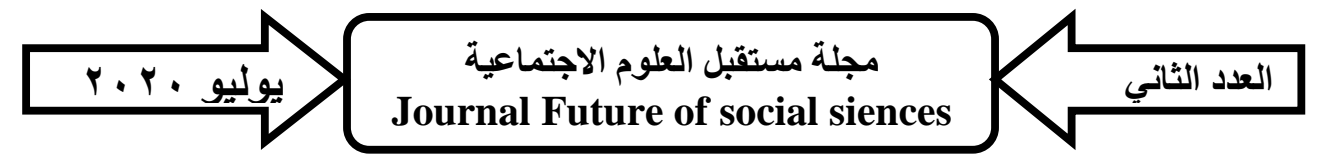

معارف ومهارات مرحلة المتابعة بعد الخروج من المؤسسة قبل وبعد تطبيق البرنامج التدربيى ، حيث اتضح من جدول رقم (YT) وجود فروق دالة إحصائيا عند مستوى معنويـة ا ., · بين القياس القبلي والقياس البعدي وذلك لصـالح القياس البعدي مما يشير إلى فعالية البرنـامج التـريبى في زيـادة معـارف ومهارات عينـة الدراسـة مـن الأخصـائيين الاجتمـاعيين الخاصـة بمرحلة المتابعة بعد الخروج من المؤسسة في إدارة الحالة. - - - - الفرض الفرعى الثامن

توجد فروق دالة إحصائيأ بين درجات عينة الأخصائيين الاجتماعيين على اختبار معارف ومهارات نموذج إدارة الحالة لتحسين نوعية حياة الأطفال بـلا مأوى فى بعد معارف ومهارات التسجيل بملف ادارة الحالة قبل وبعد تطبيق البرنامج التدريبى ، حيث اتضـح من جدول رقم وجود فروق دالة إحصائيا عند مستوى معنوية ا •, · ب بين القياس القبلي والقياس البعدي وذلك لصالح القياس البعدي مما يشير إلى فعالية البرنامج التدربيى في زيادة معارف ومهارات عينة الدراسة من الأخصائيين الاجتماعيين الخاصة بالتسجيل في إدارة الحالة ب: النتائج المتعلقة يالفرض الثانى للاراسة من المتوقع زيادة معدل إنجاز الأخصائيين الاجتماعيين لنموذج إدارة الحالة لتحسين نوعية حياة الأطفال بلا مأوى بعد التعرض للبرنامج

$$
\text { التدريبى على نموذج إدارة الحالة . }
$$

نتائج هذا الفرض اعتمدت على محكات أساسية وهى :

ا ـ نتائج تقييم قدرة الأخصائيين الاجتماعيين على تطبيق الخطوات المهنية للنموذج إدارة

الحالة وكان التقييم من جانب الأخصائيين الاجتماعيين انفسهم •

r. تحليل تسجيلات الأخصائيين الاجتماعيين من خلال استخدامهم لملف إدارة الحالة وذلك فى ضوء محتوى البرنامج التدربيى وبخطوات النموذج ومقارنة نتائج هذا التحليل · بنتائج تقييمهر

r. الاستعانة بالمؤشرات التى ذكرها (النوحى، عبدالعزيز ، ب99 19، ص • \& V) للتعرف على نجاح النموذج والتى سبق ذكرها فى النموذج • 


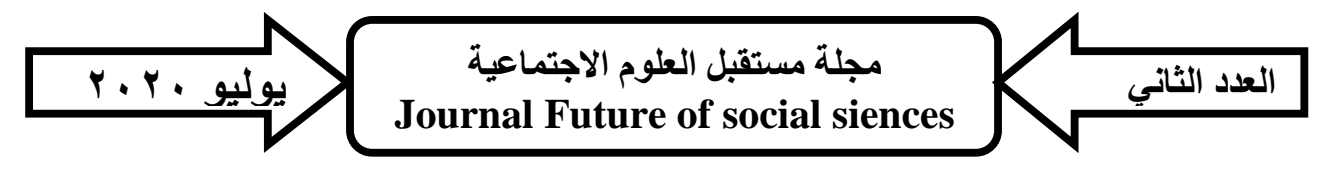

وقد كانت الهم نتائج هذا الفرض والذى يعكس مؤشرات تطبيق النموذج فى ضوء المحكات السابقة مايلى :-

- حيث اتضح من جدول رقم (Y9) معدل انجاز الاخصائيين الاجتماعيين فى تطبيق مرحلة

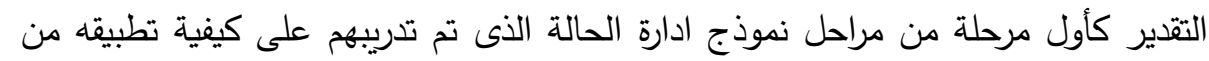

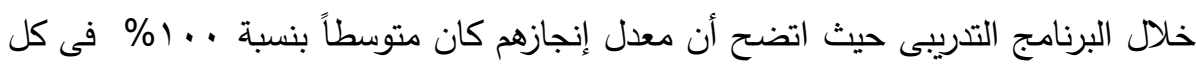

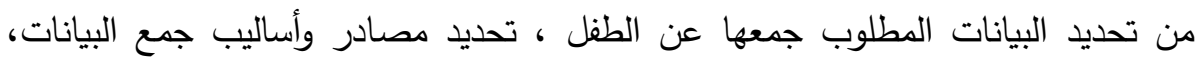

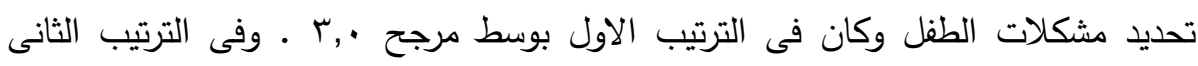

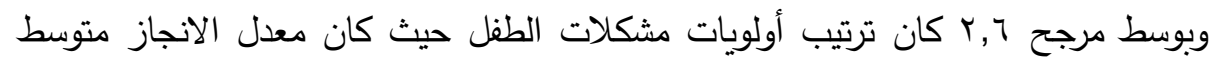

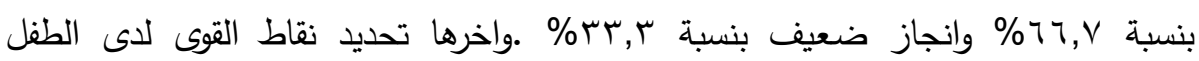

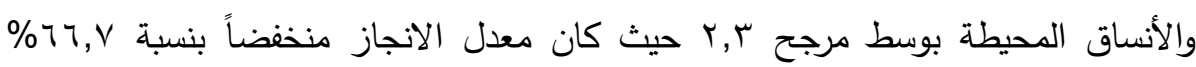
وبنسبة r,rr\%

- حيث اتضح من جدول رقم (·r) معدل إنجاز الأخصائيين الاجتماعيين فى تطبيق مرحلة

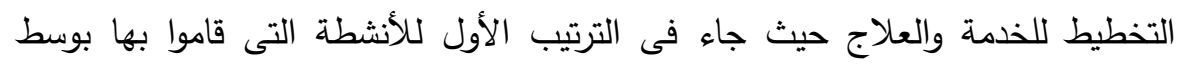

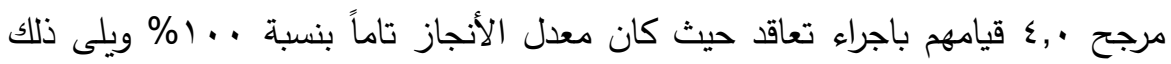

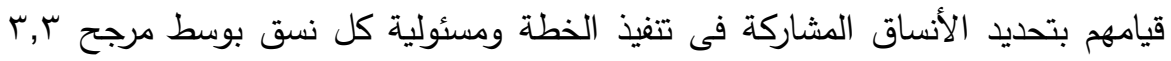

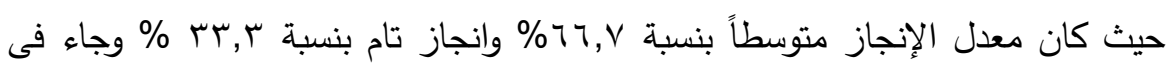

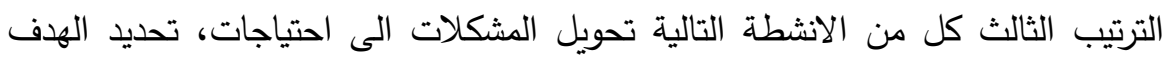

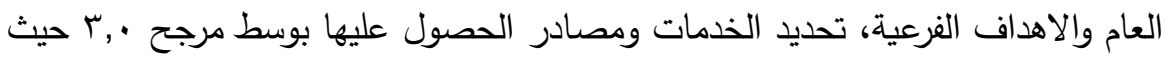
كان معدل الانجاز متوسط بنسبة ... 1\% وجاء فى الترتيب الاخير قدرتهم على تحديد

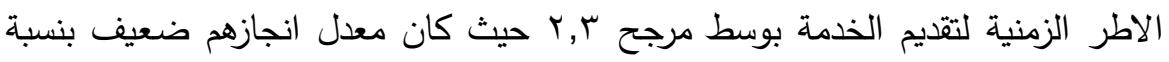

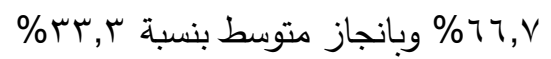

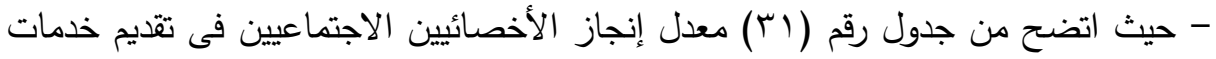

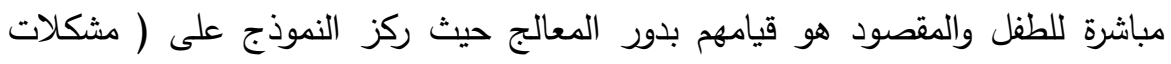

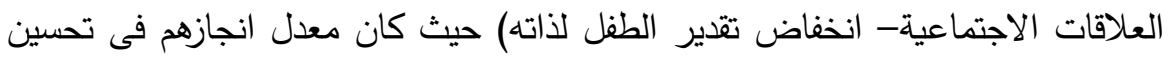

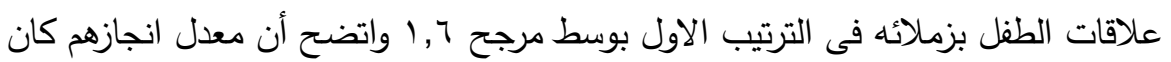

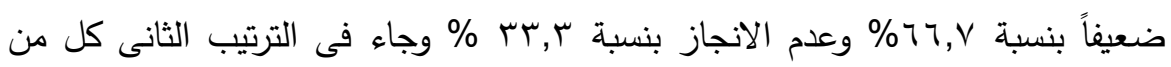
قدرتهم على تحسين تقدير الطفل لذاته و تحسين علاقات الطفل بأسرته. 


\section{بوليو · مجلة مستقبل العلوم الاجتماعية}

- حيث اتضح من جدول رقم (rr) قدرة الأخصائيين الاجتماعيين على قيامهم بدور التتسيق

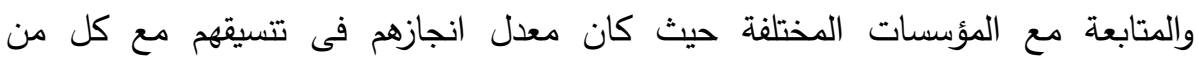
المؤسسات التعليمية والصحية فى الترتيب الأول بوسط •.r حيث كان معان معدل انجازهم متوسطاً بنسبة .,... 1\% ، بينما كان تتسيقهم مع المؤسسات النفسية فى الترتيب الاخير

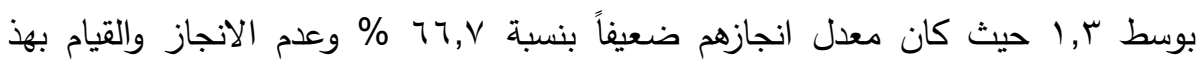

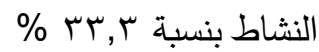

- حيث اتضح من جدول رقم (Tس) قدرة الأخصائيين الاجتماعيين على قيامه بتقديم الدعم

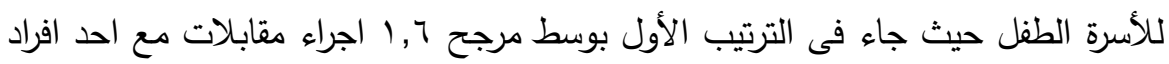

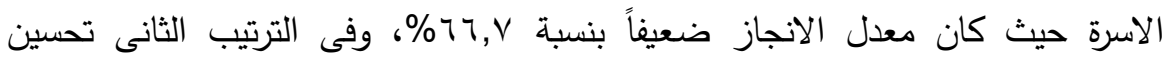

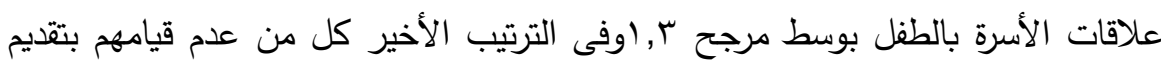

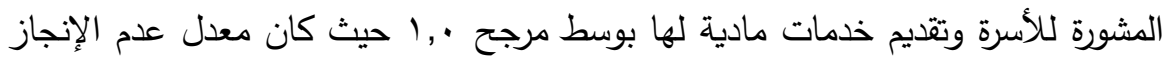

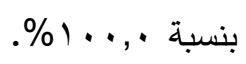

- حيث اتضح معدل إنجاز الأخصائيين الاجتماعيين فى القيام بمراحل متابعة تتفيذ الخطة والتقييم والإنهاء ومتابعة الطفل بعد خروجه من المؤسسة، حيث يتضح من الجدول انهم قاموا

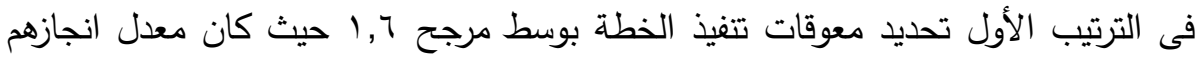

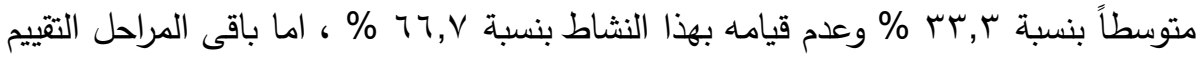

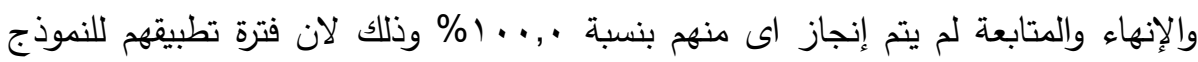

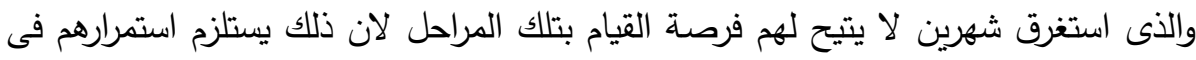

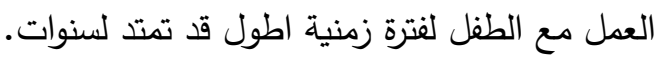

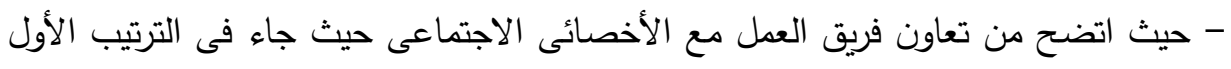

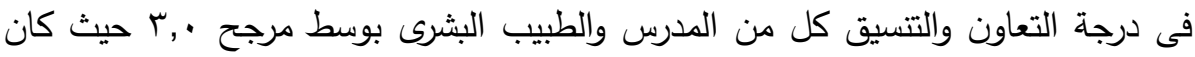

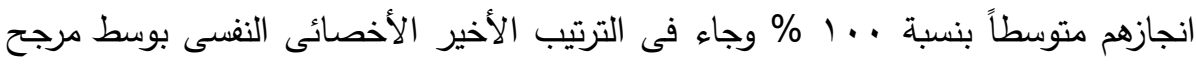

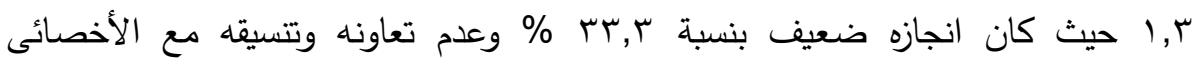

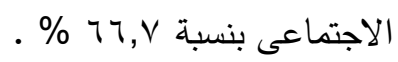

-حيث اتضح معدل إنجاز الأخصائيين الاجتماعيين فى التسجيل باستخدام ملف ادارة الحالة

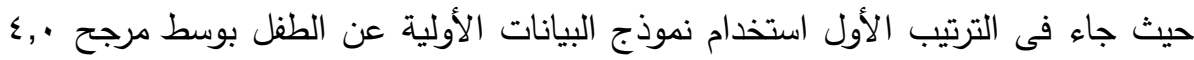

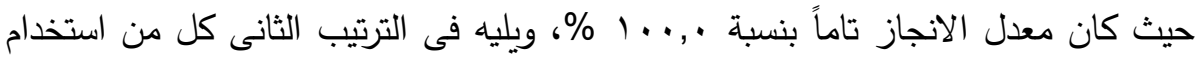




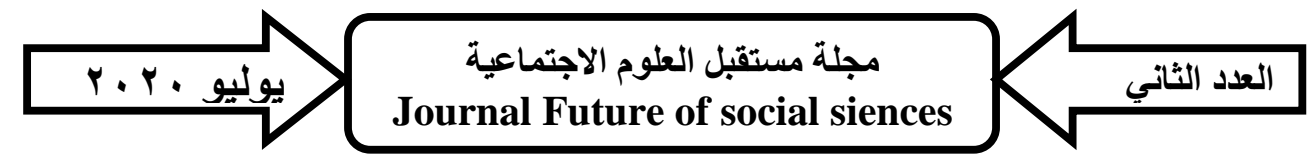

نماذج (تقدير موقف الطفل وأسرته، قائمة مشكلات الطفل، لتحديد المشكلات/ الاحتياجات/

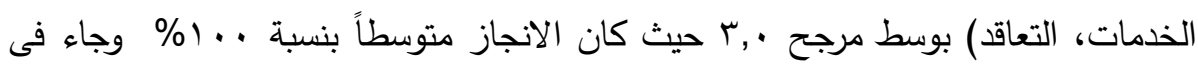
الترتيب الاخير كل من استخدام نماذج (استمارة متابعة تتفيذ الخطة، التقييم النهائى، متابعة

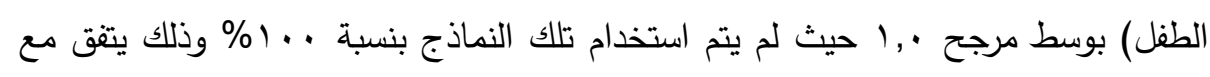
عدم قيامهم بانشطة مرحلة التقييم والانهاء والمتابعة. - ترتيب معدلات إنجاز الأخصائيون الاجتماعيون فى تطبيق خطوات نموذج إدارة الحالة من خـلال قيامهم بالعديد من الأثطة التى تحويها كل خطوة وكان ترتيب انجـازهم للخطوات كالتالى:-

$$
\text { - - - إنجازهم لانشطة مرحلة التخطيط للخدمة وتقديم العلاج }
$$

- - أنشطة التعاون مع فريق العمل والتشجيل فى ملف إدارة الحالة - تتفيذ الخطة خاصا فيما يتعلق بتقديم خدمات مباشرة للطفل والتتسيق بين مختلف

$$
\text { المؤسسات. }
$$

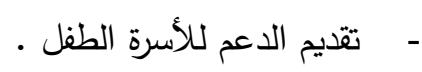

تم تحليل تسجيلاتهم التى تعكس ما قاموا به من أنشطة خلال فترة زمنية

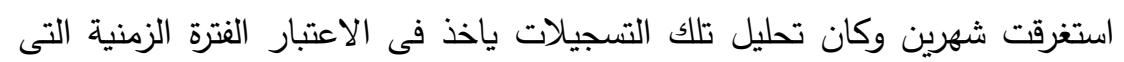
استغرقها الاخصائى الاجتماعى كمدير للحالة فى تطبيق بعض خطوات نموذج ادارة

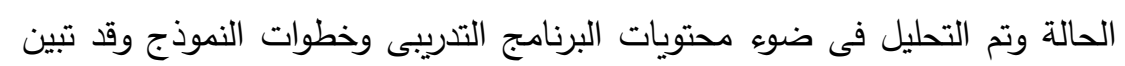
الأتى:

ا - قيامهم ببعض الانشطة التى تتعق بتقدير حالة الطفل ولكن عند التسجيل فى نموذج ادارة الحالة حدث تداخل خاصا فيما يتعلق بتقدير شخصية الطفل . r- اعتماده على بعض المصادر للحصول على البيانات والمعلومات الخاصة بالطفل.

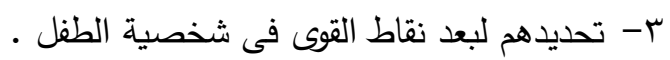
ع - تقدير بعض الجوانب الأسرية . تصائ

ه- تحديد المؤسسات التى تقدم الخدمات بالاضافة الى المؤسسة نفسها . 7- عدم صياغة بعض المشكلات التى يعانى منها الطفل صياغة مجردة - V كيفية تحويل المشكلة الى حاجة وتحديد الخدمات التى تثبع تلك الحاجة 


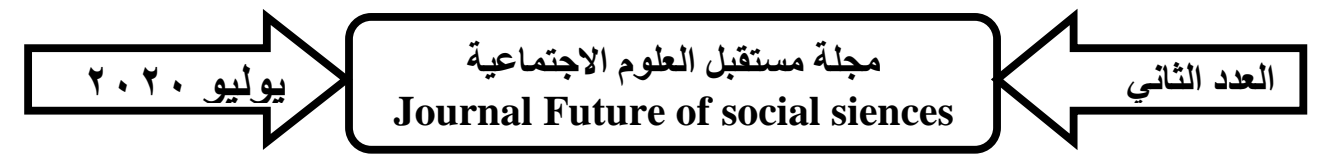

1- تحديد الأهداف العامة والأهداف الفرعية لخطة العمل.

9- اجراء تعاقد مكتوب فى صورة مبدئية.

• 1 - تقديمهم لبعض الخدمات وقيامهم ببعض الادوار مع الاطفال.

11 - وجود فريق عمل متمثل فى (اخصائى اجتماعى - مدرس - طبيب بشرى - أخصائى

نفسى) ولكن يحتاج الى زيادة وعيهح بدور مدير الحالة .

r ا - تم استخدام ملف ادارة الحالة والتسجيل فيه بطريقة جيدة .

ب ا - وجود قصور فى تواجد الطبيب النفسى فى المؤسسة ولهذا يتم التعاقد مع اخصائى ملى

$$
\text { نفسى خارج الموسسة. }
$$

ع ا - تم تحديد اولويات المشكلات من جانب الاخصائى الاجتماعى فقط وهى نقطة ضعف. وقد تم مقارنة تسجيلات الاخصائيين الاجتماعيين بملف ادارة الحالة وما يعكسه من

خطوات لتطبيق نموذج ادارة الحالة وبين نتائج تقييم قدرتهم على تطبيق النموذج واتضح انهما

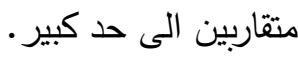

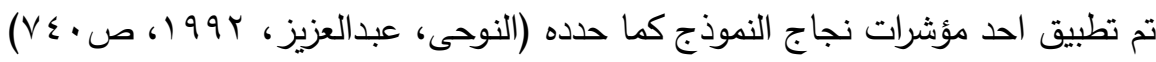
للتعرف على موشـر نجاح النموذج وهو اذا جاءت النتائج مطابقة للتوقعات او على الاقل متقاربة معها فمعنى هذا وجود مؤشر لصـلاحية النموذج للتطبيق فنجد انه فى ضوء النتائج السابقة يمكن القول بان نتائج تطبيق النموذج جاءت متقاربة الى النتائج المتوقعة من تطبيق · النموذج

وفى ضوء ما سبق عرضه من نتائج عن معدلات انجاز الاخصائين الاجتماعيين للنموذج يتضح ان للاخصائيين الاجتماعيين لديهم القدرة على القيام ببعض الأنشطة المرتبطة بخطوات النموذج واذا توفرت بعض العناصر سوف يكون معدلات انجازهم افضل ولكى يتم توفير هذه العناصر هناك بعض المقترحات للتغلب على بعض السلبيات التى واجهت التطبيق المبدئى للنموذج والتى من شأنها تساعد على تطبيق النموذج بالصورة

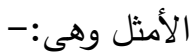

- اجراء التعديلات المؤسسية اللازمـة للتطبيق النموذج كتعديل بعض لوائح وسياسـات

$$
\text { المؤسسة. }
$$

- ايجاد مسمى وظيفى لمدير الحالة فى الموسسة. 


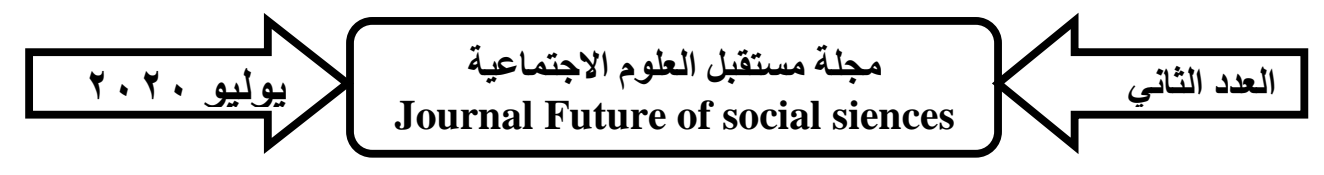

- ضرورة تفهم فريق العمل طبيعة دور مدير الحالة وهذا يتوقف على رغبة المؤسسة فى

$$
\text { ايجاد مسمى وظيفى جديد لمدير الحالة. }
$$

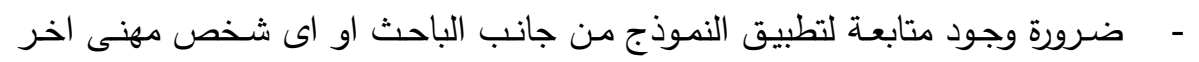

$$
\text { تحدده المؤسسة. }
$$

- - مرورة تحديد اختصاصات ومسئوليات كل عضو من أعضاء فريق العمل.

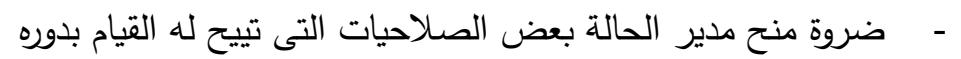

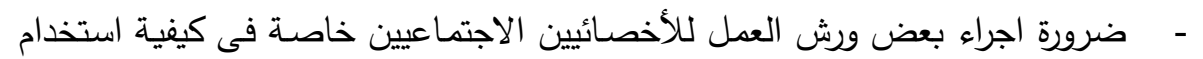
المقاييس العلمية لتقدير حالة الطفل وتقييم نتائج التدخل .

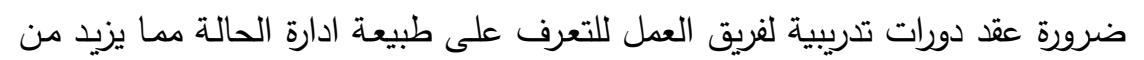

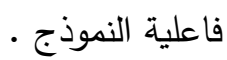

ضروة الاهتمام بإدارة الحالة واضافتها ضمن مناهج إعداد الأخصائيين الاجتماعيين •

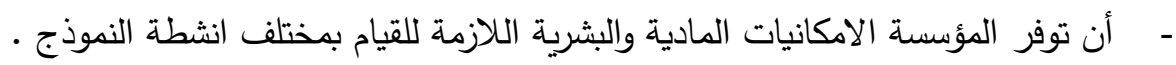

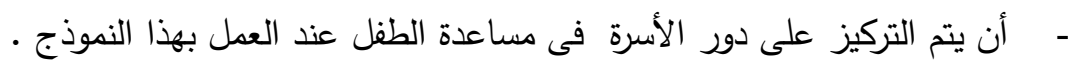
مراجع الدراسة: ابو النصر ، مدحت (ع . . ب). الاعاقة الاجتماعية الففهوم والانواع وبرامج الرعاية ، القاهرة

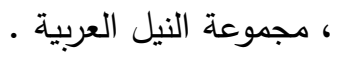

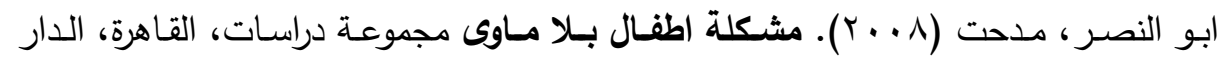

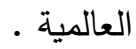

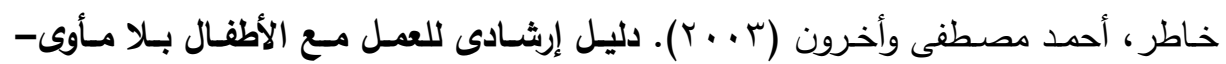

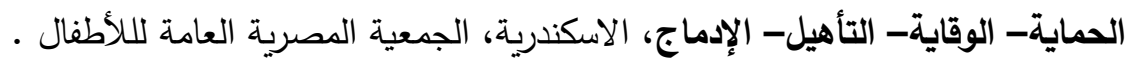

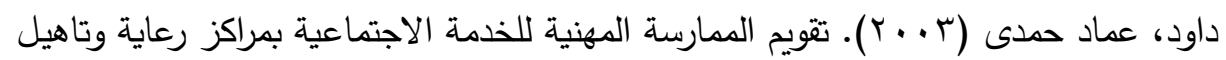
اطفال الثوارع، بحث منشور فى مجلة دراسـات في الخدمـة الاجتماعية والعلوم الانسانية، كلية الخدمة الاجتماعية - جامعة حلوان، العدد ـا، الجزء ؟.

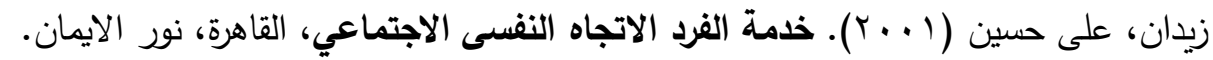

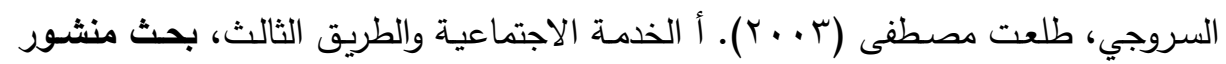

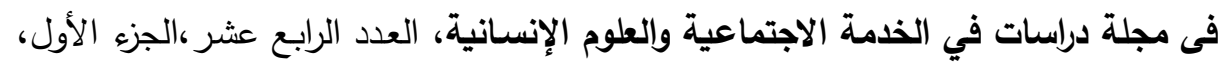

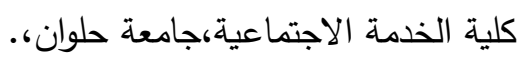




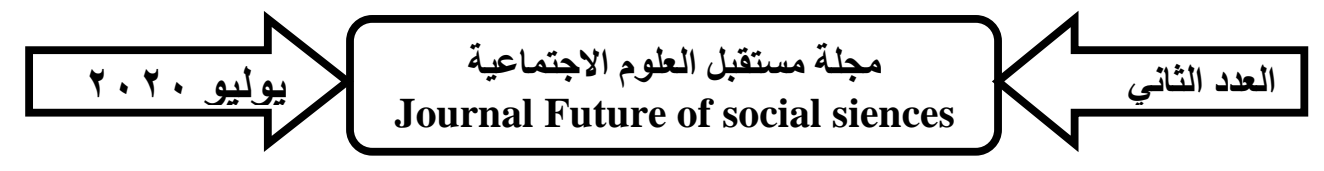

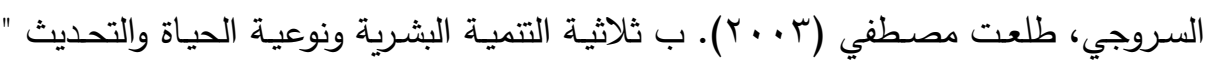

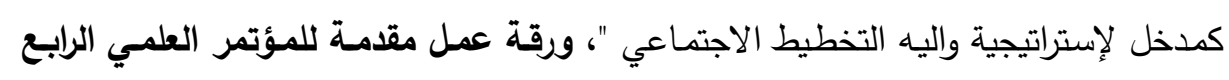
عشر، كلية الخدمة الاجتماعية، جامعة القاهرة (فرع الفيوم ).

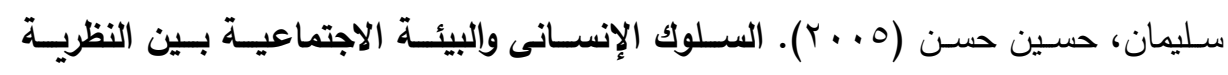

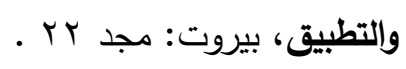

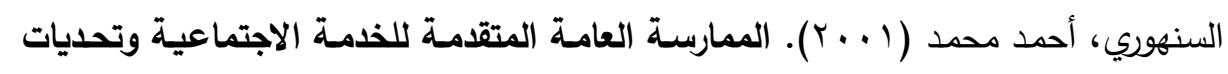

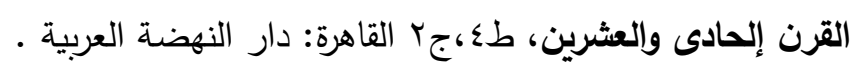

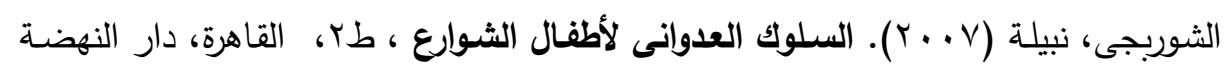

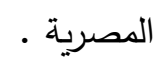

صديق، أحمد (990 (190). خبرات مع اطفال الشوارع (مركز رعاية وتتمية الطفل وحقوقه ) .

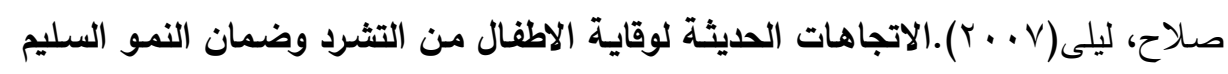

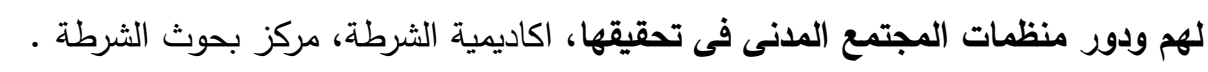

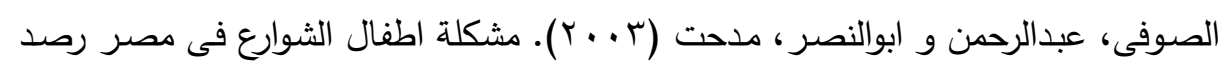

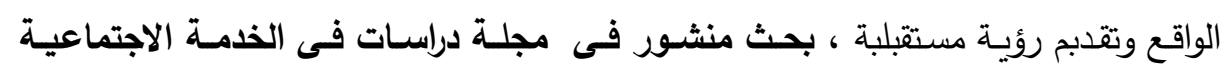

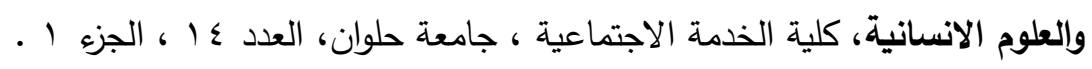

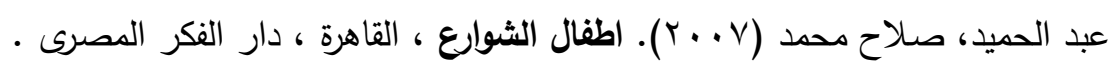

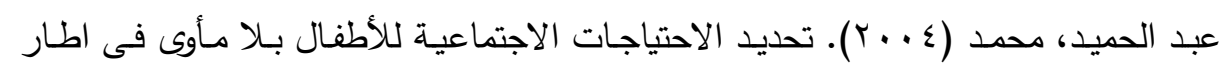

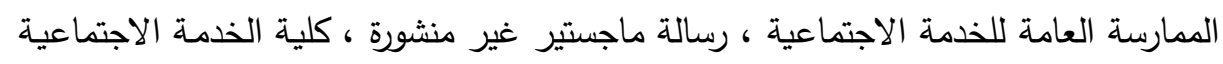

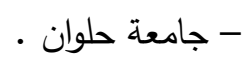
عبد المجيد، هثام سيد (T ب). البحث في الخدمة الاجتماعية الإكلينيكية، القاهرة: مكتبة الأنجلو المصرية. عثمان، عبد الفتاح (99V (1)). خدمة الفرد في إطار التعددية المعاصرة، القاهرة، مكتبة عين شمس.

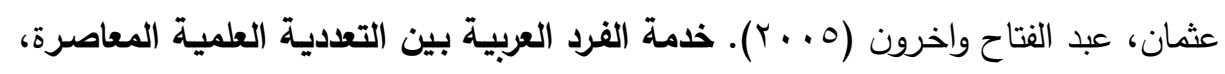
القاهرة: بل برنت للطباعة. عصر ، سامى ( . . ب). اطفال الثـوارع ( الظـاهرة والأسباب )، المنظمسة العربيـة للتربيـة

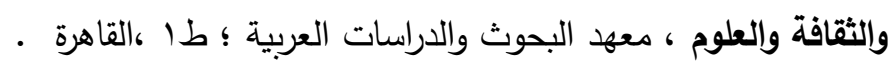




\section{r.r.r. يوليو}

مجلة مستقبل العوم الاجتماعية

Journal Future of social siences

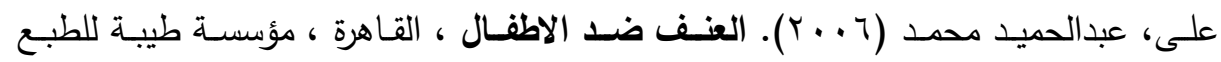
والنشر .

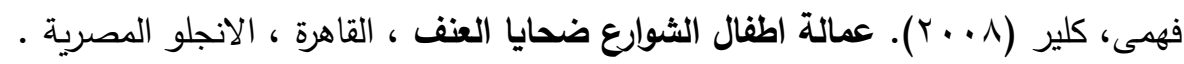

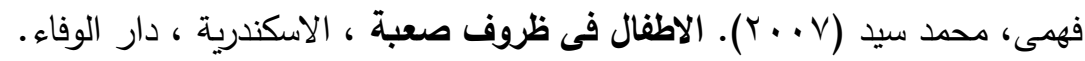

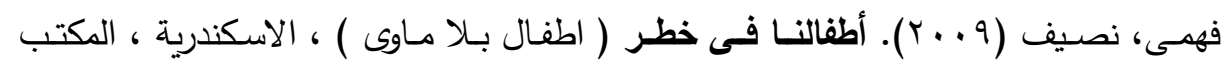

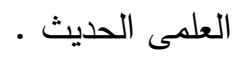

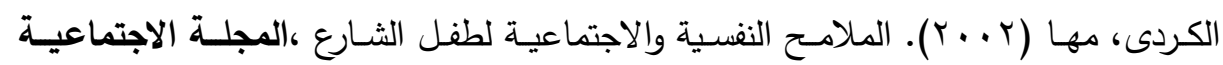

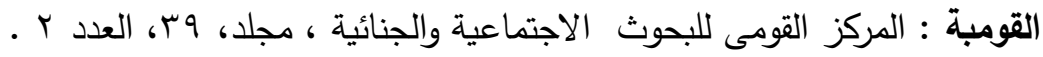

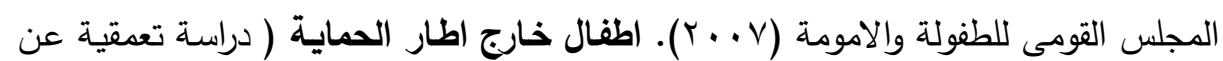
(اطفال الشوارع فى القاهرة الكبرى).

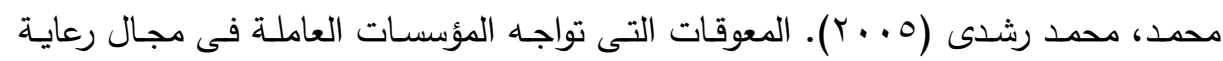

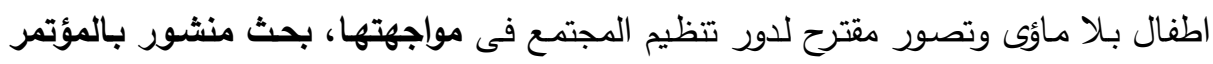

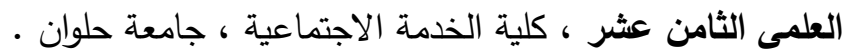

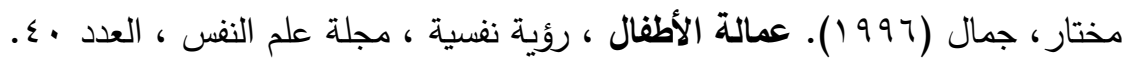

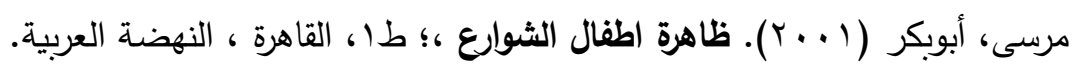

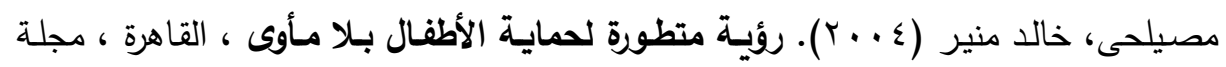

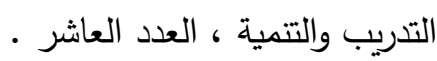

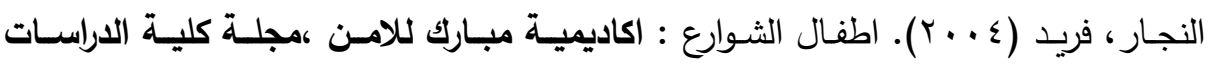

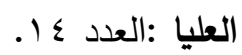

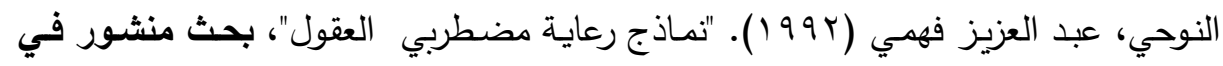

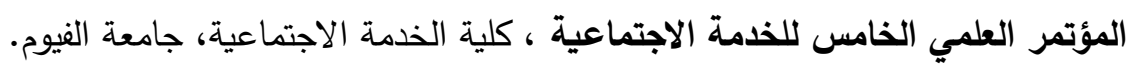

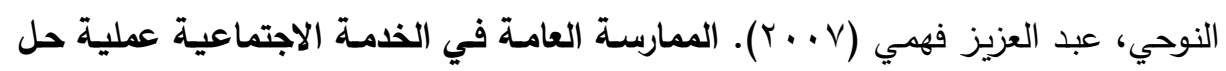

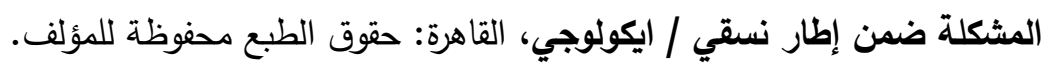

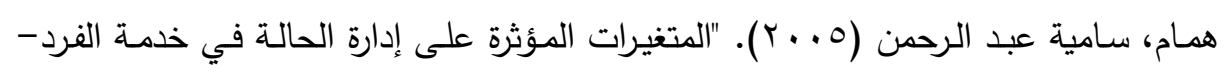

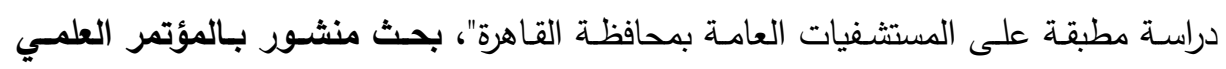
الثامن عشر للخدمة الاجتماعية ، كلية الخدمة الاجتماعية، جامعة حلوان. 


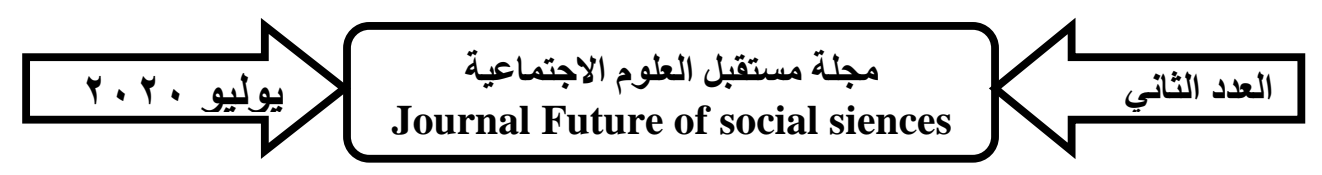

الوردانى، نبيلة (ع . . ץ). دراسة تقيمية لظاهرة اطفال الثوارع ومدى تاثيرها فى الاسرة الفقيرة، مجلة الطفولة والتنمية ،المجلس العربى للطفولة والتتمية ، العدد 10 ، مجلد ع.

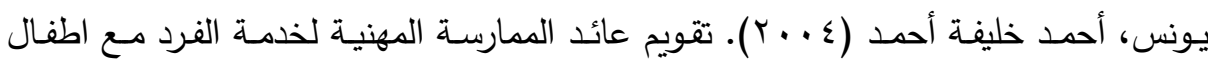
الثـوارع فـى مؤسسـات الرعايـة الاجتماعيـة، رسـالة ماجستير غيـر منشـورة ، كليـة الخدمـة

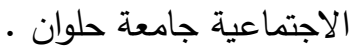
يونس، أحمد خليفة أحمد (9 . . ب). بناء نموذج لادارة الحالة فى مجال الاعاقة العقلية رسالة دكتوراة غير منشورة ، كلية الخدمة الاجتماعية ، جامعة حلوان •

A, James, et al (2002). (iowa case management: innovative social case work), NASW, Vol 47, No 2.

A, Simposn, et al (2003). Case management models and the care programme approach: how to make the CPA effective and credible, Journal of Psychiatric and Mental Health Nursing, No 10.

A, SIMPSON and L, BOWERS (2003). Case management models and the care programme approach: how to make the CPA effective and credible, Journal of Psychiatric and Mental Health Nursing 10, 472-483.

Adams, Anne Thomas, et al (2008). CASE MANAGEMENT A Resource Manual, New York.

B, Bernadette, et al (2006). First-Birth Outcomes and Timing of Second Births: A Statewide Case Management Program for Adolescent Mothers: National Association of Social Worker's 31, No 1 .

B, Janse, et al (2004). Quality of Life: Patients and Doctors Don't Always Agree, Clinical Epidemiology, Vol. 57, No. 7.

Better at home? Benefits of case management for children with complex needs (2008). Pediatric nursing، Vol 20, No 9.

Bigby, Christine, et al (2007). Planning and Support for People with Intellectual Disabilities Issues for Case Managers and Other Professionals, London, Jessica Kingsley Publishers.

Bill, House (2003). Catastrophic Case Management Report to the Texas, Legislature.

Bourdeaux, Lisa, et al (2005). Comparative Study of Case Management Program for Patients with Syncope, JOURNAL OF NURSING CARE QUAUTY/APRIL-JUNE.

Carr, Alison, et al (2003). Quality of Life, London, BMJ Books. 


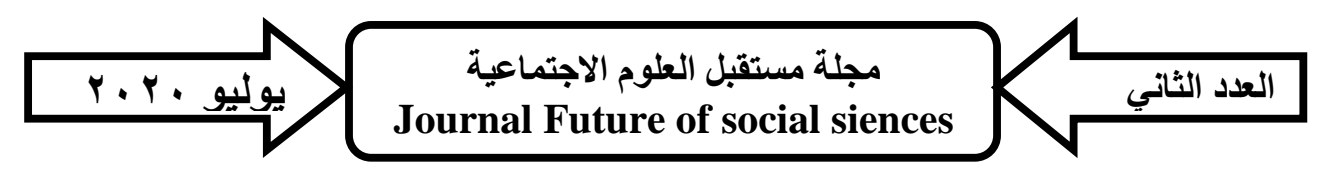

Case management (2004). A critical review, 2004 mental health practice, Vol 7, No 8.

Chi-ChiLu, et al (2007). A Pilot Study of a Case Management Program, Journal of Nursing Research, Vol 15, No 2.

Clark, Marvel (2004). The Conceptual and Operational Definition of Quality of Life "A Systematic Review of The Literature": Submitted to the Office of Graduate Studies of Texas A\&M University Texas A\&M University in partial fulfillment of the requirements for the degree of MASTER OF SCIENCE.

Clarke, Tom, et al (2002). Self-harm in adults: A randomized controlled trial of nurse-led case management versus routine care only, Journal of Mental Health, Vol 2, No 11.

Compton, Beulah and Galaway, Burt (1999). social work processes, 16 ed, Boston, Brooks/cole publishing company.

De man, Henk (2009). Case Management: A Review of Modeling Approaches, January.

flynn, patrice, et al (2002). sustainability \& quality of life indicators: toward the integration of economic, social and environmental measures, indicators: the Journal of Social Health, Vol. 1, No. 4.

Franklin, Jack, et al (1987). An Evaluation of Case Management, American Journal of Public Health, Vol. 77, No. 6.

Friedman, Myles (1997). IMPROVING THE QUALITY OF LIFE A Holistic Scientific Strategy, London, Praeger Publishers. Galloway, Susan (2005). Well- being and quality of life: measuring the benefits of culture and sport: A Literature Review in (Scottish Executive Social Research.

Goodwin, James, et al (2003). Effect of Nurse Case Management on the Treatment of Older Women with Breast Cancer, clinical investigation, Vol. 51, No. 9.

Gursansky, DI, et al (2003). Case management (policy, practice and profesional business), National Library of Australia.

H, Jannah and H, Grafton (2009). Case management and child welfare, social workers desk reference, $2^{\text {nd }}$ ed, Oxford University Press.

H, Marke, and F, Philip (2007). Towards a Typology of Case Management.

Healey, Kerry Murphy (1999). Case Management in the Criminal Justice System, U.S. Department of Justic Office of Justice Programs- National Institute of Justic. 


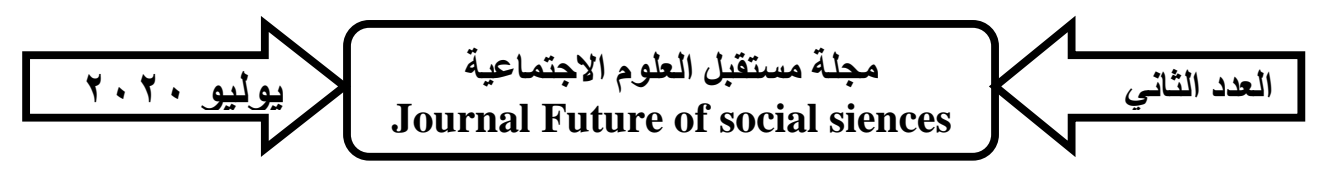

Health Care Policy / Community Supports \& Services MR/DD TCM System Change Information, June 15, (2007).

James, Karls, et al (1992). NASW Standards for Social Work Case Managemen, Washington, DC: NASW Press.

Jansson, Lauren, et al (2003). Effectiveness of Child Case Management Services for Offspring of Drug-Dependent Women, SUBSTANCE USE \& MISUSE, Vol. 38. No. 14.

K. K, Ashman and Jr. G. H, Hull (2002). Understanding Generalist Practice, $3^{\text {rd }}$ ed, Pacific Grove, CA: Brooks/Cole Thomson Learning.

Liu, Chi-pun, et al (2004). An experience of social work case management for frail elders in Hong Kong (Geriatrics and Gerontology International).

M, Payen (2000). The polities of case management and social work, international journal of social work welfare, oxford, Blackwell publishers.

Maricopa County Case Management and Clinical Team.

Mathiti, Vuyisile (2006). The quality of life of street children accommodated at three shelters in Pretoria: an exploratory study, Early Child Development and Care, Vol. 176.

Monchick, Randy, et al (2006). Drug Court Case Management Role, Function, and Utility, National Drug Court Institute.

Monchick, Randy, et al (2006). Drug Court Case Management: Role, Function, and Utility, National Drug Court Institute, the education, research, and scholarship affiliate of the National Association of Drug Court Professionals.

Moore, Stephen (1990). A social work practice model of case management: the case management grid, NASW.

Murphy, Kerry (1999). Case Management in the Criminal Justice System, National Institute of Justice, U.S. Department of Justice Office of Justice Programs.

N, Summers (2001). Fundamentals of Case Management Practice, Exercises and Readings, Belmont, CA: Brooks/Cole Thomson.

O. W, Farley, et al (2006). Introduction to Social Work, $10^{\text {th }}$ ed, Boston Pearson Education, Inc. For Patients With Chronic Obstructive Pulmonary Disease (COPD), Journal of Nursing Research, Vol 15, No 2. 


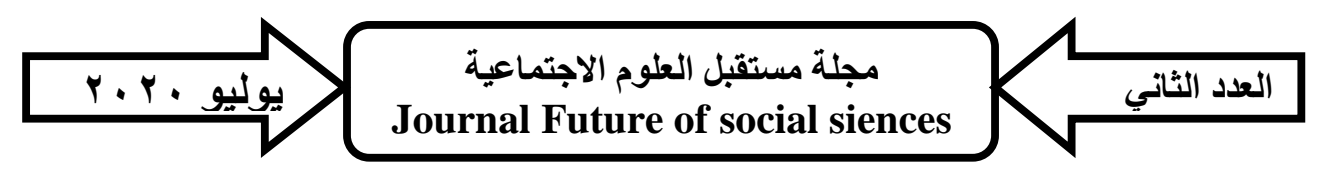

P, Lichtenberg, et al (2008). Clinical case management to frevolvingdoor Patients a semi-randomized study, Journal Compilation Blackwell Munksgaard.

Park, Jiyeon, et al (2002). Impacts of Poverty on Quality of Life in Families of Children with Disabilities, Vol. 68, No. 2.

PARK, SUNG.BOK (2005). CONCEPT OF THE QUALITY OF LIFE AND INDEXING, International Review of Public Administration, Vol. 9, No. 2.

Philipe, Popple and Leslie, Leighninger (2002). Social Work, Social Welfare, and American Society, $5^{\text {th }}$ ed, Boston: Allyn and Bacon.

Phillips, David (2003). Quality of Life Concept, policy and practice, london, Routledge, 2006.

Pieper, Richard and Vaarama, Marja (2008). Care-Related Quality of Life in Old Age Concepts, Models and Empirical Findings, New York, Springer.

R. 1, Barker (1999). The Social Work Dictionary, $4^{\text {th }}$ ed, Washington, DC: NASW Press.

Rahman, Tauhidur, et al (2003). Measuring the Quality of Life across Countries: A Sensitivity Analysis of Well-Being Indices, The paper prepared for presentation at WIDER International conference on Inequality, Poverty and Human Well-Being, May 3031, Helsinki, Finland.

Rosen, Alan and Teesson, Maree (2001). Does case management work? The evidence and the abuse of evidence-based medicine, Australian and New Zealand Journal of Psychiatry, No 35.

Rosen, Alan and Teesson, Maree (2001). Does case management work? The evidence and the abuse of evidence-based medicine) Australian and New Zealand Journal of Psychiatry.

Rules of Conduct for Case Managers Serving People with Developmental Disabilities, (Health Care Policy Community Supports \& Services) (2003).

S. M, Rose, and V. L, Moore (1995). "Case Management", in Encyclopedia of Social Work, $19^{\text {th }}$ ed, Washington, DC: NASW Press, Vol 1.

S. W, Boyle, et al (2006). Direct Practice in Social Work, Boston: Pearson Education, Inc. 


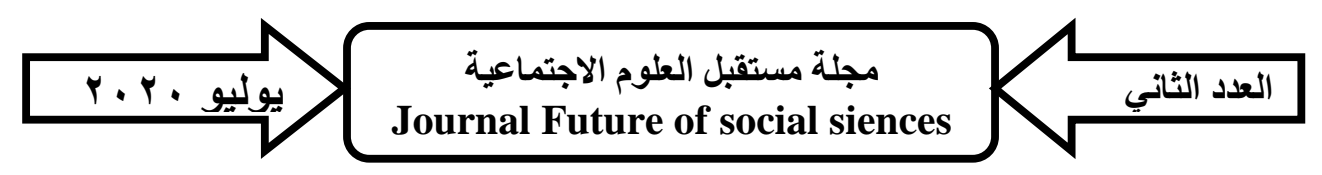

Schalock, Robert (2001). 'Three Decades of Quality of Life ،' Focus on Autism \& Other Developmental Disabilities ،Vol. 15, No. 2.

Services Plan (2001). Arizona Department of Health Services/Division of Behavioral Health Services and Maricopa County Regional Behavioral Health Authority.

Simpson, et al (2003). Case management models and the care programme approach: how to make the CPA effective and credible, Journal of Psychiatric and Mental Health Nursing.

Social Work Best Practice Healthcare Case Management Standards (2005).

Soren, Ventegodt, et al (2003). Quality of Life Theory. The IQOL Theory: An Integrative Theory of the Global Quality of Life Concept. The Scientific World JOURNAL.

Svirskis, Tanja, et al (2007). Quality of life and functioning ability in subjects vulnerable to psychosis, Comprehensive Psychiatry.

T, Diana, et al (1996). Case management: a review of the definition and practices, journal of advanced nursing, No 29.

T, Diana, et al (1996). Case management: a review of the definition and practices, journal of advanced nursing.

$\mathrm{T}$, Elizabeth, et al (2002). The general method of social work practice, Boston, Pearson Education.

Tuberculosis case management for nurses (2008). FUNDAMENTALS OF TUBERCULOSIS CASE MANAGEMENT, module 2.

Vfantopoulos, J (2001). Quality of life in the measurement of health, qalys and the standard gamble.

Weiss, Marianne (1999). Case Management Transforming to Meet the Demands of an Evolving Healthcare System, Dis Manage Health Outcomes, No 6.

World health organization (1994). Programme on substance abuse street children, substance use and health: training for street educators

Worrall, Linda and Holland, Audrey (2003). Special issue: quality of life in aphasia, psychogogy press, Vol 17, No 4. 